\title{
Buckling of Laminated Elliptical and Super-Elliptical Thin Plates
}

\author{
Erkin ALTUNSARAY ${ }^{1}$ \\ İsmail BAYER ${ }^{2}$
}

\begin{abstract}
In this computational study the buckling analysis of symmetrically laminated elliptical and super-elliptical thin plates was carried out. The plates were considered as clamped or simply supported at the boundary. The minimum buckling load was determined using the RayleighRitz method and the Galerkin Method based on the Classical Laminated Plate Theory (CLPT). The influence of the solution methods, shape functions, boundary conditions, superelliptical power, lamination type, aspect ratio, and thickness on the critical buckling load were investigated using a parametric study. The verification of the isotropic case was performed comparing some results in the open literature, and good agreement was obtained. Convergence studies of the composite case with increasing terms (up to 10 terms) were achieved and sufficient accuracy was provided. During the preliminary design stage of composite structures, many design parameters such as panel sizes, panel thickness, stacking sequences, boundary conditions and loading conditions are taken into consideration. It is possible to evaluate these parameters quickly by using appropriate shape functions with the Rayleigh-Ritz method.
\end{abstract}

Keywords: Super-elliptical composite thin plates, buckling, Classic Laminated Plate Theory (CLPT), Rayleigh-Ritz method, The Galerkin Method, shape function.

\section{INTRODUCTION}

Composite panels have high specific strength and high specific rigidity, which are the most important advantages especially when compared to steel structures. Hence, they are used in engineering applications such as civil, aerospace and marine engineering as building materials [1-3]. With developing technology, analysis of super-elliptical plates under wind loads has been studied recently [4]. For the accurate designing of structures, it is important to analyze their critical buckling loads. Numerous studies on the buckling of composite

\footnotetext{
Note:

- This paper was received on December 11, 2020 and accepted for publication by the Editorial Board on July 7, 2021.

- Discussions on this paper will be accepted by November 30, 2022.

- https://doi.org/10.18400/tekderg.839435

1 Dokuz Eylul University, Institute of Marine Sciences and Technology, Izmir, Turkey erkin.altunsaray@deu.edu.tr - https://orcid.org/0000-0003-3099-6059

2 Yildiz Technical University, Department of Naval Architecture and Marine Engineering, Istanbul, Turkey bayer@yildiz.edu.tr - https://orcid.org/0000-0002-8589-671X
} 
rectangular, elliptical or circular plates analyzed by the Rayleigh-Ritz method have been demonstrated in the review paper [5].

The buckling of rectangular isotropic plates was studied by Timoshenko and Gere [6] and Szilard [7]. Dawe and Craig [8] analyzed the buckling and vibration of rectangular laminated plates subject to in-plane stress systems using the Rayleigh-Ritz Method and the finite strip method based on shear deformation plate theory. Leissa [9] presented a review of laminated composite plate buckling from the extensive available literature. Aiello and Ombres [10] examined the buckling and vibration of unsymmetrical rectangular laminates resting on elastic foundations under in-plane and shear forces.

The authors have used the Rayleigh-Ritz Method based on the-first order shear deformation theory. Darvizeh et al. [11], studied the buckling analysis of generally laminated composite rectangular plates by generalized differential quadrature rules and the Rayleigh-Ritz Method. The authors compared the results with some available experimental and analytical results. Reddy [12] presented the buckling analysis of orthotropic and anisotropic rectangular plates by using analytical and numerical methods. Shufrin et al. [13] dealt with the buckling of laminated composite plates for general boundary conditions using the semi-analytical Kantorovich method. Seifi et al. [14] presented the critical buckling loads and related buckling modes of cross-ply laminated annular plates using the Rayleigh-Ritz Method and finite element analysis based on Classical Laminate Plate Theory (CLPT).

Altunsaray and Bayer [15] presented the buckling of symmetrically laminated quasi-isotropic rectangular plates by using the Finite Difference Method, the Galerkin Method and the Finite Element Method (ANSYS software). Afsharmanesh et al. [16] examined the buckling and vibration of laminated composite angle-ply and cross-ply circular plates on a Winkler-type foundation by the Ritz Method and the Finite Element Method (ABAQUS software). Ghaheri et al. [17] studied the buckling and vibration of symmetrically laminated angle-ply and crossply composite elliptical plates on an elastic foundation using the Ritz Method.

Rectangular plates having rounded corners are named as super-elliptical plates having the advantage of diffusing the stress at the corner of rectangular plates [18]. The buckling of isotropic, thin, super-elliptical plates was studied at first by Wang et al. [19]. Solutions were obtained by using the Rayleigh-Ritz Method based on the Kirchhoff-Love theory in this study [19]. Altekin [20] studied the free linear vibration and buckling of isotropic superelliptical plates resting on symmetrically distributed point-supports on the diagonals by using the Rayleigh-Ritz Method and Lagrange multipliers. Hasheminejad et al. [21] investigated the dynamic stability of isotropic super-elliptical plates resting on elastic foundations under periodic in-plane loads. The Galerkin procedure is used based on the thin plate small deflection theory. Jazi and Farhatnia [22] examined the buckling analysis of a functionally graded super elliptical plate. They obtained their results by using the Rayleigh-Ritz Method based on classical plate theory for clamped and simply supported boundary conditions. Sayyad and Ghugal [23] investigated the buckling analysis of isotropic and laminated crossply composite rectangular plates, subjected to in-plane uniaxial and biaxial compressions, based on a new trigonometric shear and normal deformation theory.

Ghaheri et al. [24] demonstrated the analyses of composite plates (cross-ply and angle-ply) resting on Winkler-type foundations subject to in-plane harmonic loads, under different edge conditions (clamped, simply supported and free). The authors found that the static and 
parametric characteristics were influenced by fiber orientation, stacking sequences, superelliptical power, aspect ratio, foundation stiffness parameter and in-plane loads. Zhang [25] studied the nonlinear bending and thermal post-buckling analysis of functionally graded super elliptical thin plates by using the Rayleigh-Ritz method based on the Classical Laminated Plate Theory (CLPT). Bending and free transverse vibration of shear deformable super-elliptical plates were analyzed based on the Mindlin plate theory using the finite element method by Altekin [4, 26]. Mirzaei [27] investigated the thermal buckling response of functionally graded super elliptical plates reinforced with carbon nano tubes. The author performed the parametric analyses based on the first-order shear deformation plate theory with the aid of the Ritz method.

The reason for the preference of the symmetrically laminated plates in production was explained in the study of Altunsaray and Bayer [28]. The vibration analysis of symmetrically laminated quasi-isotropic super-elliptical thin plates has been presented by the author [29]. The buckling analysis of symmetrically laminated rectangular thin plates under biaxial compression was studied by Altunsaray and Bayer [30] recently.

This paper is a development of previous work [30] studied by the authors. In their previous studies, the authors examined the biaxial buckling analyzes of simply supported laminated quasi-isotropic, cross-ply and angle-ply rectangular plates according to the Classical Laminated Plate Theory (CLPT). In this study, unlike previous studies and other studies in the open literature; laminated quasi-isotropic, cross-ply and angle-ply elliptical and superelliptical plates were investigated with Rayleigh-Ritz Method and Galerkin Method, which is known to be a powerful method among the weighted residual methods. Three different shape functions were considered at the beginning of this analysis, one of which was chosen for the parametric investigation, because it was more favorable than the other two in terms of accuracy and computing time. It has been shown that the Rayleigh-Ritz Method is more suitable than Galerkin Method for this particular problem, which is the buckling analysis of both elliptical and super-elliptic plates in simple support and clamped boundary conditions.

In this parametric study, the effects of the super-elliptical power (n), lamination type, boundary conditions (simply supported and clamped) and the aspect ratio (a/b and b/a) on the critical buckling load of symmetrically laminated quasi-isotropic, cross-ply and angleply super-elliptical thin plates were investigated.

The verification of the isotropic case was investigated by comparing the results of buckling of isotropic plates only available in the literature. The convergence study for the buckling of LT1 $\left(\left[-45_{2} / 0_{2} / 45_{2} / 90_{2}\right]_{\mathrm{s}}\right)$ plate was performed up to 10 terms, hence sufficient accuracy was obtained. The critical buckling loads of symmetrically laminated plates with different superelliptical powers, lamination types, boundary conditions and aspect ratios have also been presented with tables and graphics.

\section{EQUATIONS AND FORMULATION}

The periphery of a super-elliptical plate between an ellipse and a rectangle is shown in (Fig. 1). 


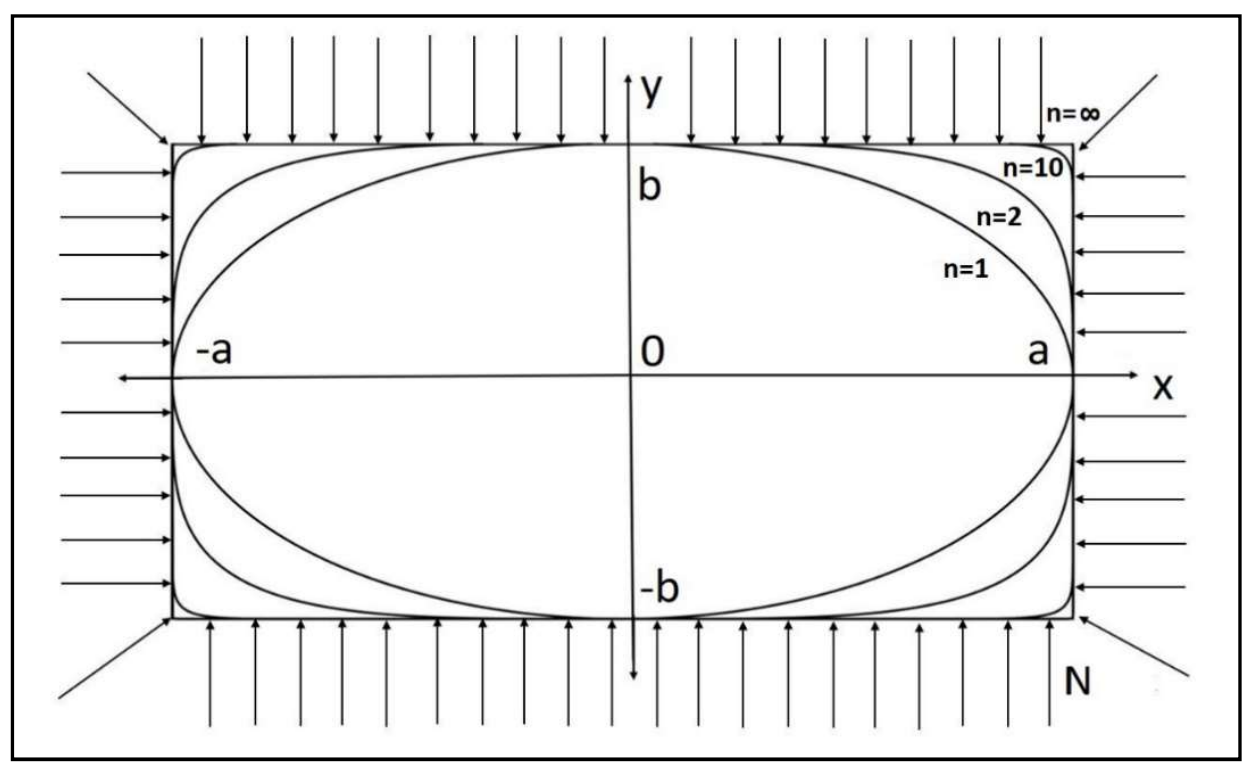

Figure 1 - Geometry of super-elliptical plate in the Cartesian co-ordinates

The equation of the super-ellipse is given in Eq. (1), where $\mathrm{n}$ is the power of the super ellipse $(n=1$ is an ellipse and $n=\infty$ is a rectangle); $a$ and $b$ are the half lengths of the plate.

$\frac{x^{2 n}}{a^{2 n}}+\frac{y^{2 n}}{b^{2 n}}=1, \quad n=1,2 \ldots \infty$

The plates in this study are considered to be within the scope of the Classical Laminated Plate Theory (CLPT), because the ratio of thickness to the short side of plates is small enough. The Rayleigh-Ritz Method and The Galerkin Method were used for the analyses.

\subsection{The Rayleigh-Ritz Method}

The strain energy (U) of the symmetrically laminated plate is given by the following expression [12]:

$U=\frac{1}{2} \int_{-a}^{a} \int_{-b \sqrt[2 n]{b} \sqrt[2 n]{1-\frac{x^{2 n}}{a^{2 n}}}}^{2 n}\left[\begin{array}{c}D_{11}\left(\frac{\partial^{2} w}{\partial x^{2}}\right)^{2}+2 D_{12}\left(\frac{\partial^{2} w}{\partial x^{2}}\right)\left(\frac{\partial^{2} w}{\partial y^{2}}\right)+D_{22}\left(\frac{\partial^{2} w}{\partial y^{2}}\right)^{2} \\ +4 D_{16}\left(\frac{\partial^{2} w}{\partial x^{2}}\right)\left(\frac{\partial^{2} w}{\partial x \partial y}\right)+4 D_{26}\left(\frac{\partial^{2} w}{\partial y^{2}}\right)\left(\frac{\partial^{2} w}{\partial x \partial y}\right)+4 D_{66}\left(\frac{\partial^{2} w}{\partial x \partial y}\right)^{2}\end{array}\right] d x d y$

where $\mathrm{w}$ indicates the transverse deflection, and $\mathrm{D}_{11}, \mathrm{D}_{12}, \mathrm{D}_{22}, \mathrm{D}_{16}, \mathrm{D}_{26}, \mathrm{D}_{66}$ denote the elements of the bending stiffness matrix $\mathrm{D}_{\mathrm{ij}}$ which are found by the following [12]:

$D_{i j}=\frac{1}{3} \sum_{k=1}^{N} \bar{Q}_{i j}^{k}\left(z_{k+1}^{3}-z_{k}^{3}\right)$ 
where $\left(\bar{Q}_{i j}\right)$ indicates the transformed reduced stiffness matrix, while $\mathrm{n}$ is the total number of plies. $z_{k}$ and $z_{k-1}$ are the distance from the reference plane [12]: Calculation of members of transformed reduced stiffness matrix $\left(\bar{Q}_{i j}\right)$ ) for each lamina is

$\bar{Q}_{11}=Q_{11} c^{4}+2\left(Q_{12}+2 Q_{66}\right) s^{2} c^{2}+Q_{22} s^{4}$

$\bar{Q}_{12}=\left(Q_{11}+Q_{22}-4 Q_{66}\right) s^{2} c^{2}+Q_{12}\left(s^{4}+c^{4}\right)$

$\bar{Q}_{22}=Q_{11} s^{4}+2\left(Q_{12}+2 Q_{66}\right) s^{2} c^{2}+Q_{22} c^{4}$

$\bar{Q}_{16}=\left(Q_{11}-Q_{12}-2 Q_{66}\right) s c^{3}+\left(Q_{12}-Q_{22}+2 Q_{66}\right) s^{3} c$

$\bar{Q}_{26}=\left(Q_{11}-Q_{12}-2 Q_{66}\right) s^{3} c+\left(Q_{12}-Q_{22}+2 Q_{66}\right) s c^{3}$

$\bar{Q}_{66}=\left(Q_{11}+Q_{22}-2 Q_{12}-2 Q_{66}\right) s^{2} c^{2}+Q_{66}\left(s^{4}+c^{4}\right)$

where $\mathrm{c}=\cos (\theta), \mathrm{s}=\sin (\theta)$ and $\theta$ is angle of the lamina, respectively. The reduced stiffness matrix elements $Q_{i j}$ are given below

$Q_{11}=\frac{E_{11}}{1-v_{12} v_{21}}$

$Q_{12}=\frac{v_{12} E_{11}}{1-v_{12} v_{21}}$

$Q_{22}=\frac{E_{22}}{1-v_{12} v_{21}}$,

$Q_{66}=G_{12}$

The potential energy of the uniform in-plane load $(\mathrm{N})$ acting on the periphery of the symmetrically laminated plate, in other words the work done by this external load, is given below [12]:

$V=-\frac{1}{2} \int_{-a}^{a} \int_{-b \sqrt[2 n]{1-\frac{x^{2 n}}{a^{2 n}}}}^{2 n} \sqrt{1-\frac{x^{2 n}}{a^{2 n}}} N\left[\left(\frac{\partial w}{\partial x}\right)^{2}+\left(\frac{\partial w}{\partial y}\right)^{2}\right] d x d y$

Then the total potential energy functional may be given as follows:

$F=U-V$

Substituting Eq. (2) and Eq. (6) into Eq. (7), the total potential energy is 


$$
F=\frac{1}{2} \int_{-a}^{a} \int_{-b}^{b} \sqrt[2 n]{1-\frac{x^{2 n}}{a^{2 n}}} \sqrt[c]{1-\frac{x^{2 n}}{a^{2 n}}}\left[\begin{array}{c}
D_{11}\left(\frac{\partial^{2} w}{\partial x^{2}}\right)^{2}+2 D_{12}\left(\frac{\partial^{2} w}{\partial x^{2}}\right)\left(\frac{\partial^{2} w}{\partial y^{2}}\right)+D_{22}\left(\frac{\partial^{2} w}{\partial y^{2}}\right)^{2} \\
\left.-N D_{16}\left(\frac{\partial^{2} w}{\partial x^{2}}\right)\left(\frac{\partial^{2} w}{\partial x \partial y}\right)+4 D_{26}\left(\frac{\partial^{2} w}{\partial y^{2}}\right)\left(\frac{\partial^{2} w}{\partial x \partial y}\right)+4 D_{66}\left(\frac{\partial^{2} w}{\partial x \partial y}\right)^{2}+\left(\frac{\partial w}{\partial y}\right)^{2}\right]
\end{array}\right] d x d y
$$

The boundary conditions at the plate edges are given below:

$$
\begin{aligned}
& w=0 \quad \text { and } \quad \mathrm{M}=0 \quad \text { (for simply supported plates) } \\
& w=0 \quad \text { and } \quad \frac{\partial w}{\partial n_{i}}=0 \quad \text { (for clamped plates) }
\end{aligned}
$$

where $\mathrm{M}$ indicates the bending moment, $\partial n_{\mathrm{i}}$ is the outward normal of the periphery. The trial function is

$\varphi_{i j}=\left(\begin{array}{l}c_{00}+c_{02} y^{2}+c_{20} x^{2}+c_{22} x^{2} y^{2}+c_{24} x^{2} y^{4}+c_{04} y^{4} \\ +c_{40} x^{4}+c_{42} x^{4} y^{2}+c_{06} y^{6}+c_{60} x^{6}\end{array}\right)$

$c_{i j}$ denotes the unknown coefficients and order of polynomial (r) is 6 . The deflection function which satisfies the boundary conditions is given below

$$
w(x, y)=\left(\frac{x^{2 n}}{a^{2 n}}+\frac{y^{2 n}}{b^{2 n}}-1\right)^{p} \varphi_{i j}
$$

$\mathrm{p}$ denotes the boundary condition ( $\mathrm{p}=1$ for simply supported condition, $\mathrm{p}=2$ for clamped condition).

In order to find the lowest critical buckling loads, Eq. (8) is minimized with respect to the coefficients $c_{i j}$

$\frac{\partial F}{C_{i j}}=0$

Then, the following equation is obtained for a non-trivial solution:

$\left|K-\lambda_{b} M_{b}\right|=0$

where $\lambda_{b}$ is the buckling load parameter including material properties, characteristic dimensions and in-plane uniform load of the plate. $\mathrm{K}$ is the stiffness matrix related to the strain energy and $M_{b}$ is the mass matrix related to potential energy. This is a generalized eigenvalue problem.

The solution of Eq. (14) leads to a characteristic equation involving a polynomial of tenth degree in $\lambda_{b}$, from which the lowest critical buckling loads $\left(\mathrm{N}_{\mathrm{cr}}\right)$ may be found. 


\subsection{The Galerkin Method}

The Galerkin Method is known as one of the powerful weighted residual methods. The governing differential equation of symmetrically laminated composite plates under in-plane load is given below:

$D_{11}\left(\frac{\partial^{4} w}{\partial x^{4}}\right)+4 D_{16}\left(\frac{\partial^{4} w}{\partial x^{3} \partial y}\right)+2\left(D_{12}+2 D_{66}\right)\left(\frac{\partial^{4} w}{\partial x^{2} \partial y^{2}}\right)+4 D_{26}\left(\frac{\partial^{4} w}{\partial x \partial y^{3}}\right)+D_{22}\left(\frac{\partial^{4} w}{\partial y^{4}}\right)+$

$N\left[\left(\frac{\partial^{2} w}{\partial x^{2}}\right)+\left(\frac{\partial^{2} w}{\partial y^{2}}\right)\right]=0$

Where $\mathrm{w}$ indicates the deflection function, and $\mathrm{D}_{11}, \mathrm{D}_{12}, \mathrm{D}_{22}, \mathrm{D}_{16}, \mathrm{D}_{26}, \mathrm{D}_{66}$ denote the elements of the bending stiffness matrix $\mathrm{D}_{\mathrm{ij}}$ which are already found in the Section 2.1.

Obviously, a residual $\left(\varepsilon_{R}\right)$ is obtained if the deflection function (Equation 12) is inserted in the governing differential equation (Equation 15), because an approximate solution to the problem is searched. The Galerkin Method minimizes the integral of the product of this residual $\left(\varepsilon_{\mathrm{R}}\right)$ and the trial function $\left(\varphi_{i j}\right)$ over the super-elliptic region.

$\int_{-a}^{a} \int_{-b}^{b} \sqrt[2 n]{1-\frac{x^{2 n}}{a^{2 n}}} \varepsilon_{R} \varphi_{i j} d x d y=0$

The rest of the calculation will be similar to the above as expressed for Rayleigh-Ritz method. A set of homogeneous linear algebraic equations in the unknown displacement $w$, whose determinant must be identically zero, is obtained. The lowest value of $\mathrm{N}_{\mathrm{cr}}$ that makes the determinant zero is the lowest critical compressive load.

\section{NUMERICAL RESULTS}

Critical buckling loads of isotropic and quasi-isotropic, cross-ply and angle-ply elliptical and super-elliptical plates under clamped and simply supported boundary conditions were calculated by the Rayleigh-Ritz method and the Galerkin Method based on the Classical Laminated Plate Theory (CLPT). Verification of the isotropic case, convergence study, and the effects of thickness, super-elliptical power (n), aspect ratio and boundary conditions on the critical buckling load are investigated in this section.

\subsection{Verification of the isotropic case}

The critical buckling load (Ncr) of elliptical $(n=1)$ thin isotropic plates under two different boundary conditions (simply supported or clamped) were compared with the results of Sato $[31,32]$ and Ghaheri et al. [17] given in Table 1. The results of the present study given in Table 1 seem to be in good agreement with the results of previous studies. Critical buckling loads decrease with the increase of the aspect ratio $(a / b)$ in both simply supported and clamped condition cases. The deflection function $(\mathrm{r}=6)$ used in the verification calculations was given in Eq. (12). 
Table 1 - Comparison of the critical buckling load $\left(N_{c r}\right)$ of elliptical $(n=1)$ isotropic plates under different edge conditions $(v=0.3, r=6)$ obtained with Rayleigh-Ritz Method

\begin{tabular}{|c|c|c|c|c|c|c|}
\hline \multirow{2}{*}{ a/b } & \multicolumn{3}{|c|}{ Simply Supported } & \multicolumn{3}{c|}{ Clamped } \\
\cline { 2 - 7 } & Sato [31] & Ghaheri et al.[17] & Present study & Sato [32] & $\begin{array}{c}\text { Ghaheri } \\
\text { et } \\
\text { al.[17] }\end{array}$ & $\begin{array}{c}\text { Present } \\
\text { study }\end{array}$ \\
\hline 1 & 4.198 & 4.198 & 4.198 & 14.682 & 14.682 & 14.682 \\
\hline 2 & 3.051 & 3.051 & 3.051 & 10.434 & 10.434 & 10.434 \\
\hline 3 & 2.911 & 2.911 & 2.911 & 9.966 & 9.966 & 9.969 \\
\hline 4 & 2.820 & 2.820 & 2.820 & 9.803 & 9.803 & 9.825 \\
\hline 5 & 2.757 & 2.757 & 2.757 & 9.721 & 9.736 & 9.796 \\
\hline
\end{tabular}

\subsection{Main parameters for composite case}

In this study T300-934 coded carbon/epoxy selected as the plate material for numerical calculations. Mechanical properties of carbon/epoxy are given in Table 2 [33].

Table 2 - Mechanical properties of carbon/epoxy (T300-934) [33]

\begin{tabular}{|l|l|}
\hline Longitudinal Young Modulus $\left(\mathrm{E}_{11}\right)$ & $148 \times 10^{9}\left(\mathrm{~N} / \mathrm{m}^{2}\right)$ \\
\hline Transversal Young Modulus $\left(\mathrm{E}_{22}\right)$ & $9.65 \times 10^{9}\left(\mathrm{~N} / \mathrm{m}^{2}\right)$ \\
\hline Longitudinal Shear Modulus $\left(\mathrm{G}_{12}\right)$ & $4.55 \times 10^{9}\left(\mathrm{~N} / \mathrm{m}^{2}\right)$ \\
\hline Longitudinal Poisson ratio $\left(v_{12}\right)$ & 0.3 \\
\hline Lamina thickness $(\mathrm{t})$ & $0.185 \times 10^{-3}-0.213 \times 10^{-3}(\mathrm{~m})$ \\
\hline
\end{tabular}

The short half side ( $a$ or $b$ ) is selected as $0.1 \mathrm{~m}$. Six different aspect ratios $(\mathrm{a} / \mathrm{b}$ or $\mathrm{b} / \mathrm{a}=1,1.2$, $1.4,1.6,1.8,2)$ are considered. Twenty-eight different types of symmetrically laminated quasi-isotropic, cross-ply and angle-ply super-elliptical plates are given in Table 3. Quasiisotropic plates have four different sequences $\left(-45^{\circ}, 0^{\circ}, 45^{\circ}\right.$ and $\left.90^{\circ}\right)$, cross-ply laminated plates consist of two different sequences $\left(0^{\circ}\right.$ and $\left.90^{\circ}\right)$ and angle-ply laminates have two different sequences $\left(-45^{\circ}\right.$ and $\left.45^{\circ}\right)$. Thickness of each lamina $(\mathrm{t})$ is equal to $0.2 \mathrm{~mm}$ and total thickness of a plate is $3.2 \mathrm{~mm}$.

Table 3 - Symmetrically laminated composite plate types

\begin{tabular}{|l|l|l|l|}
\hline LT1 & {$\left[-45_{2} / 0_{2} / 45_{2} / 90_{2}\right]_{\mathrm{s}}$} & LT15 & {$\left[45_{2} / 0_{2} /-45_{2} / 90_{2}\right]_{\mathrm{s}}$} \\
\hline LT2 & {$\left[-45_{2} / 0_{2} / 90_{2} / 45_{2}\right]_{\mathrm{s}}$} & LT16 & {$\left[45_{2} / 0_{2} / 90_{2} /-45_{2}\right]_{\mathrm{s}}$} \\
\hline LT3 & {$\left[-45_{2} / 45_{2} / 0_{2} / 90_{2}\right]_{\mathrm{s}}$} & LT17 & {$\left[45_{2} / 99_{02} /-45_{2} / 0_{2}\right]_{\mathrm{s}}$} \\
\hline LT4 & {$\left[-45_{2} / 45_{2} / 90_{2} / 0_{2}\right]_{\mathrm{s}}$} & LT18 & {$\left[45_{2} / 90_{2} / 0_{2} /-45_{2}\right]_{\mathrm{s}}$} \\
\hline
\end{tabular}


Table 3 - Symmetrically laminated composite plate types (continue)

\begin{tabular}{|l|l|l|l|}
\hline LT5 & {$\left[-45_{2} / 90_{2} / 0_{2} / 45_{2}\right]_{\mathrm{s}}$} & LT19 & {$\left[90_{2} /-45_{2} / 0_{2} / 45_{2}\right]_{\mathrm{s}}$} \\
\hline LT6 & {$\left[-45_{2} / 90_{2} / 45_{2} / 0_{2}\right]_{\mathrm{s}}$} & LT20 & {$\left[90_{2} /-45_{2} / 45_{2} / 0_{2}\right]_{\mathrm{s}}$} \\
\hline LT7 & {$\left[0_{2} /-45_{2} / 45_{2} / 90_{2}\right]_{\mathrm{s}}$} & $\mathbf{L T 2 1}$ & {$\left[90_{2} / 0_{2} /-45_{2} / 45_{2}\right]_{\mathrm{s}}$} \\
\hline LT8 & {$\left[0_{2} /-45_{2} / 90_{2} / 45_{2}\right]_{\mathrm{s}}$} & LT22 & {$\left[90_{2} / 0_{2} / 45_{2} /-45_{2}\right]_{\mathrm{s}}$} \\
\hline LT9 & {$\left[0_{2} / 45_{2} /-45_{2} / 90_{2}\right]_{\mathrm{s}}$} & $\mathbf{L T 2 3}$ & {$\left[90_{2} / 45_{2} /-45_{2} / 0_{2}\right]_{\mathrm{s}}$} \\
\hline LT10 & {$\left[0_{2} / 45_{2} / 90_{2} /-45_{2}\right]_{\mathrm{s}}$} & $\mathbf{L T 2 4}$ & {$\left[90_{2} / 45_{2} / 0_{2} /-45_{2}\right]_{\mathrm{s}}$} \\
\hline LT11 & {$\left[0_{2} / 90_{2} /-45_{2} / 45_{2}\right]_{\mathrm{s}}$} & $\mathbf{L T 2 5}$ & {$\left[0_{2} / 90_{2} / 0_{2} / 90_{2}\right]_{\mathrm{s}}$} \\
\hline LT12 & {$\left[0_{2} / 90_{2} / 45_{2} /-45_{2}\right]_{\mathrm{s}}$} & LT26 & {$\left[90_{2} / 0_{2} / 90_{2} / 0_{2}\right]_{\mathrm{s}}$} \\
\hline LT13 & {$\left[45_{2} /-45_{2} / 0_{2} / 90_{2}\right]_{\mathrm{s}}$} & LT27 & {$\left[-45_{2} / 45_{2} /-45_{2} / 45_{2}\right]_{\mathrm{s}}$} \\
\hline LT14 & {$\left[45_{2} /-45_{2} / 90_{2} / 0_{2}\right]_{\mathrm{s}}$} & LT28 & {$\left[45_{2} /-45_{2} / 45_{2} /-45_{2}\right]_{\mathrm{s}}$} \\
\hline
\end{tabular}

\subsection{Convergence study}

Critical buckling loads of LT1 ( $\left[-45_{2} / 0_{2} / 45_{2} / 90_{2}\right] \mathrm{s}$ ) plates with different support conditions (clamped or simply supported), for super-elliptical powers ( $\mathrm{n}=1$ and 10$)$, for three different shape functions (Table 4) and for two solution methods (The Galerkin Method and The Rayleigh-Ritz Method) with increasing terms were calculated in order to reach convergence.

Table 4 - Selected three different deflection functions ( $p=1$ for simply supported plate, $p=2$ for clamped plate)

\begin{tabular}{|c|c|}
\hline & Deflection Functions \\
\hline df1 & $w=\left(\frac{x^{2 n}}{a^{2 n}}+\frac{y^{2 n}}{b^{2 n}}-1\right)^{p}\left(c_{00}+c_{20} x^{2}+c_{02} y^{2}+c_{22} x^{2} y^{2}+c_{40} x^{4}\right)$ \\
\hline $\mathrm{df} 2$ & $w=\left(\frac{x^{2 n}}{a^{2 n}}+\frac{y^{2 n}}{b^{2 n}}-1\right)^{p}\left(c_{00}+c_{20} \frac{x^{2}}{a^{2}}+c_{02} \frac{y^{2}}{b^{2}}+c_{22} \frac{x^{2}}{a^{2}} \frac{y^{2}}{b^{2}}+c_{40} \frac{x^{4}}{a^{4}}\right)$ \\
\hline df3 & $\begin{aligned} w=\left(\frac{x^{2 n}}{a^{2 n}}+\frac{y^{2 n}}{b^{2 n}}\right. & -1)^{p}\left(c_{0}+c_{1}\left(\frac{x^{2 n}}{a^{2 n}}+\frac{y^{2 n}}{b^{2 n}}-1\right)^{1}+c_{2}\left(\frac{x^{2 n}}{a^{2 n}}+\frac{y^{2 n}}{b^{2 n}}-1\right)^{2}\right. \\
& +c_{3}\left(\frac{x^{2 n}}{a^{2 n}}+\frac{y^{2 n}}{b^{2 n}}-1\right)^{3}+c_{4}\left(\frac{x^{2 n}}{a^{2 n}}+\frac{y^{2 n}}{b^{2 n}}-1\right)^{4} \\
& \left.+c_{5}\left(\frac{x^{2 n}}{a^{2 n}}+\frac{y^{2 n}}{b^{2 n}}-1\right)^{5}\right)\end{aligned}$ \\
\hline
\end{tabular}




\subsection{Effect of Super-Elliptical Power (n), Boundary Condition, Method of Solution and Deflection Function}

In this section the effect of super-elliptical power (n), boundary condition, method of solution and deflection function on the critical buckling load have been investigated and presented (Table 5-6) for LT1 ([-45 $\left.\left./ 0_{2} / 45_{2} / 90_{2}\right] \mathrm{s}\right)$ plate. Critical buckling loads obtained by RayleighRitz Method and Galerkin Method (for elliptical plate with clamped edge, that is, $n=1$ ) are compared in Table 6. If the same shape functions are used, the same results were found with two different solution methods (Galerkin Method and Rayleigh-Ritz Method), as Reddy stated [12]. However, results were obtained much more rapidly with Rayleigh-Ritz method compared with the Galerkin Method. In addition, the results obtained by df1 and df 2 were the same for both methods. Although the results calculated by using df3 are close to df1 and df 2 in the case of elliptical plate $(n=1)$, the solution required a longer processing time. The use of df3 did not yield accurate results for both simply supported edge and clamped edge. For both elliptical $(n=1)$ and super-elliptical plates $(n=10)$, df1 was found to be the most suitable option for the calculations. One of the reasons for not arriving at any results by the Galerkin Method for simply supported edge may be that there are fourth-degree derivatives in the governing differential equation used. Therefore, when the Galerkin Method is applied some derivative expressions disappear due to the shape function used during the calculation for the simple support boundary condition. On the other hand, because there are quadratic derivative expressions in the integral equation, such a problem does not occur in the solution with the Rayleigh-Ritz Method. After this investigation it was decided to use Rayleigh-Ritz Method with df1 with up to 10 terms for the rest of the study.

Table 5 - Convergence study of critical buckling load $N_{c r}(\mathrm{~N} / \mathrm{m})$ of super-elliptical LT1 ( $\left.\left[-45_{2} / 0_{2} / 45_{2} / 90_{2}\right] \mathrm{s}\right)$ plate (clamped)

\begin{tabular}{|c|c|c|c|c|c|}
\hline $\mathrm{n}=1$ & \multicolumn{5}{|c|}{ Critical buckling load $\mathrm{N}_{\mathrm{cr}}(\mathrm{N} / \mathrm{m})$} \\
\hline \multirow{2}{*}{ Method of solution } & \multicolumn{5}{|c|}{ Increasing terms } \\
\hline & 1 & 2 & 3 & 4 & 5 \\
\hline Rayleigh-Ritz (df1) & 272939 & 254156 & 248606 & 248518 & 248476 \\
\hline Rayleigh-Ritz (df2) & 272939 & 254156 & 248606 & 248518 & 248476 \\
\hline Rayleigh-Ritz (df3) & 272939 & 250793 & 250457 & 250455 & 250455 \\
\hline Galerkin (df1) & 272939 & 254156 & 248606 & 248518 & 248476 \\
\hline Galerkin (df2) & 272939 & 254156 & 248606 & 248518 & 248476 \\
\hline Galerkin (df3) & 272939 & 250793 & 250457 & 250455 & 250455 \\
\hline $\mathrm{n}=\mathbf{1 0}$ & \multicolumn{5}{|c|}{ Critical buckling load $\mathrm{N}_{\mathrm{cr}}(\mathrm{N} / \mathrm{m})$} \\
\hline \multirow{2}{*}{ Method of solution } & \multicolumn{5}{|c|}{ Increasing terms } \\
\hline & 1 & 2 & 3 & 4 & 5 \\
\hline Rayleigh-Ritz (df1) & 12505200 & 6319280 & 3593230 & 912713 & 656662 \\
\hline Rayleigh-Ritz (df2) & 12505200 & 6319280 & 3593230 & 912713 & 656662 \\
\hline Rayleigh-Ritz (df3) & 12505200 & 6616170 & 4836340 & 3963080 & 3437660 \\
\hline
\end{tabular}


Table 6 - Convergence study of critical buckling load $N_{c r}(\mathrm{~N} / \mathrm{m})$ of super-elliptical LT1 ( $\left[-45_{2} / 0_{2} / 45_{2} / 90_{2}\right] \mathrm{s}$ ) plate (simply supported)

\begin{tabular}{|l|c|c|c|c|c|}
\hline \multirow{2}{*}{ n=1 } & \multicolumn{5}{|c|}{ Critical buckling load Nor (N/m) } \\
\hline \multirow{2}{*}{ Method of solution } & \multicolumn{5}{|c|}{ Increasing terms } \\
\cline { 2 - 6 } & $\mathbf{1}$ & $\mathbf{2}$ & $\mathbf{3}$ & $\mathbf{4}$ & $\mathbf{5}$ \\
\hline Rayleigh-Ritz (df1) & 89787 & 80186,4 & 72271,2 & 72154,8 & 72147,8 \\
\hline Rayleigh-Ritz (df2) & 89787 & 80186,4 & 72271,2 & 72154,8 & 72147,8 \\
\hline Rayleigh-Ritz (df3) & 89787 & 72375,4 & 72297,5 & 72297,4 & 72297,4 \\
\hline n=10 & \multicolumn{5}{|c|}{ Increasing terms } \\
\hline \multirow{2}{*}{ Method of solution } & $\mathbf{1}$ & $\mathbf{2}$ & $\mathbf{3}$ & $\mathbf{4}$ & $\mathbf{5}$ \\
\cline { 2 - 6 } & $\mathbf{1}$ & 6003250 & 1592030 & 219160 & 185974 \\
\hline Rayleigh-Ritz (df1) & 6004240 & 6003250 & 1592030 & 219160 & 185974 \\
\hline Rayleigh-Ritz (df2) & 6004240 & $6040)$ & 978255 \\
\hline Rayleigh-Ritz (df3) & 6004240 & 2089610 & 1416880 & 1135030 & buckling load Non (N/m) \\
\hline
\end{tabular}

It can be observed from Table 7 that the convergence achieved is sufficient, if a shape function with 10 terms $(\mathrm{r}=6)$ is selected. Hence this shape function will be used for all calculations for the rest of the study.

Table 7 - Convergence study of critical buckling load $N_{c r}(N / m)$ of LT1 ( $\left.\left[-45_{2} / 0_{2} / 45_{2} / 90_{2}\right] s\right)$ with the Rayleigh-Ritz Method

\begin{tabular}{|c|c|c|c|c|}
\hline \multirow{2}{*}{ Shape functions } & \multicolumn{3}{|c|}{ Critical buckling load N (N/m) } \\
\cline { 2 - 5 } & Simply Supported & \multicolumn{2}{|c|}{ Clamped } \\
\cline { 2 - 5 } & $\mathbf{n}=\mathbf{1}$ & $\mathbf{n}=\mathbf{1 0}$ & $\mathbf{n}=\mathbf{1}$ & $\mathbf{n = 1 0}$ \\
\hline$c_{00}$ & 89787.0 & 6004240 & 272939 & 12505200 \\
\hline$c_{00}+c_{20} x^{2}$ & 80186.4 & 6003250 & 254156 & 6319280 \\
\hline$c_{00}+c_{20} x^{2}+c_{02} y^{2}$ & 72271.2 & 1592030 & 248606 & 3593230 \\
\hline$c_{00}+c_{20} x^{2}+c_{02} y^{2}+c_{22} x^{2} y^{2}$ & 72154.8 & 219160 & 248518 & 912713 \\
\hline$c_{00}+c_{20} x^{2}+c_{02} y^{2}+c_{22} x^{2} y^{2}+c_{40} x^{4}$ & 72147.8 & 185974 & 248476 & 656662 \\
\hline$c_{00}+c_{20} x^{2}+c_{02} y^{2}+c_{22} x^{2} y^{2}+c_{40} x^{4}+c_{04} y^{4}$ & 72129.9 & 156480 & 248018 & 511536 \\
\hline$c_{00}+c_{20} x^{2}+c_{02} y^{2}+c_{22} x^{2} y^{2}+c_{24} x^{2} y^{4}+c_{40} x^{4}+c_{04}$ & & & & \\
$y^{4}$ & 72129.8 & 144653 & 248017 & 436023 \\
\hline$c_{00}+c_{20} x^{2}+c_{02} y^{2}+c_{22} x^{2} y^{2}+c_{24} x^{2} y^{4}+c_{40} x^{4}$ & & & & \\
$+c_{04} y^{4}+c_{42} x^{4} y^{2}$ & 72129.6 & 101350 & 248017 & 244432 \\
\hline$c_{00}+c_{20} x^{2}+c_{02} y^{2}+c_{22} x^{2} y^{2}+c_{24} x^{2} y^{4}+c_{40} x^{4}$ & & & & \\
$+c_{04} y^{4}+c_{42} x^{4} y^{2}+c_{60} x^{6}$ & 72129.6 & 100192 & 248017 & 239047 \\
\hline$c_{00}+c_{20} x^{2}+c_{02} y^{2}+c_{22} x^{2} y^{2}+c_{24} x^{2} y^{4}+c_{40} x^{4}+c_{04}$ & & & & \\
$y^{4}+c_{42} x^{4} y^{2}+c_{60} x^{6}+c_{06} y^{6}$ & 72129.6 & 99773.5 & 248012 & 235721 \\
\hline
\end{tabular}




\subsection{Effect of super-elliptical power (n)}

The effect of some selected super-elliptical powers $(n=1,2,4,6,8,10)$ on the critical buckling loads of super-elliptical plate LT1 ([-45 $\left.\left./ 02 / 45_{2} / 90_{2}\right] \mathrm{s}\right)$ was investigated and the results are presented in Table 8-9. From the results one can see that the critical buckling load $\left(\mathrm{N}_{\mathrm{cr}}\right)$ generally increases with the increase of the super-elliptical power (n), while $\mathrm{N}_{\mathrm{cr}}$ decreases with the increase of the aspect ratios ( $a / b, b / a)$.

It is interesting to see from the results of simply supported boundary conditions (Table 8) that critical buckling loads for $n=1$ (elliptical plates) and $n=2$ are lower than rectangular plates. A similar situation is observed in clamped boundary conditions for $n=2$ and 4 cases (Table 9). As shown in Table 7, in the analyzes performed it was only possible to reach a maximum of 10 terms $(\mathrm{r}=6)$ and a super-elliptical power up to $\mathrm{n}=10$ using Wolfram Mathematica software. Analyses for higher number of terms and super-elliptical powers can be achieved by using computers with high computational capacity.

Table 8 - Critical buckling load $N_{c r}(\mathrm{~N} / \mathrm{m})$ of super-elliptical LT1 ( [-45 $\left.2 / \mathrm{O}_{2} / 45_{2} / 90_{2}\right] \mathrm{s}$ ) plate (simply supported $r=6$ )

\begin{tabular}{|c|c|c|c|c|c|c|c|}
\hline \multirow{2}{*}{$\mathbf{a} / \mathbf{b}$} & \multicolumn{7}{|c|}{ Critical buckling load (N/m) } \\
\cline { 2 - 8 } & $\mathbf{n = 1}$ & $\mathbf{n = 2}$ & $\mathbf{n = 4}$ & $\mathbf{n = 6}$ & $\mathbf{n = 8}$ & $\mathbf{n = 1 0}$ & Rectangle [30] \\
\hline 1 & 72129.6 & 76729.2 & 87361.9 & 92150.8 & 95897.9 & 99773.5 & 87155 \\
\hline 1.2 & 56678.2 & 60865.7 & 69666.9 & 73602.3 & 76632.1 & 79719.0 & 69227 \\
\hline 1.4 & 48209.8 & 51387.6 & 58590 & 61823.4 & 64343.9 & 66955.8 & 57983 \\
\hline 1.6 & 43197.7 & 45287.7 & 51168.7 & 53835.6 & 55979.2 & 58289.4 & 50452 \\
\hline 1.8 & 40029.5 & 41137.5 & 45950.3 & 48161.7 & 50006.7 & 52089.7 & 45166 \\
\hline 2.0 & 37906.3 & 38188.8 & 42143.9 & 43988.4 & 45589.4 & 47474.9 & 41321 \\
\hline $\mathbf{b} / \mathbf{a}$ & & & & & & & \\
\hline 1 & 72129.6 & 76729.2 & 87361.9 & 92150.8 & 95897.9 & 99773.5 & 87155 \\
\hline 1.2 & 66815.0 & 69286.9 & 77740.7 & 81619 & 84801.6 & 88295.5 & 77739 \\
\hline 1.4 & 64334.6 & 64893.8 & 71564.1 & 74693.7 & 77397 & 80591.1 & 71597 \\
\hline 1.6 & 63049.7 & 62100.2 & 67353.7 & 69884.2 & 72175.9 & 75087. & 67340 \\
\hline 1.8 & 62278.9 & 60219. & 64356.1 & 66415.6 & 68346.2 & 71001.7 & 64265 \\
\hline 2 & 61729.0 & 58892.3 & 62147.8 & 63841.6 & 65463.7 & 67858.6 & 61971 \\
\hline
\end{tabular}

Table 9 - Critical buckling load $N_{c r}(\mathrm{~N} / \mathrm{m})$ of super-elliptical LT1 ( [-45 $\left.2 / \mathrm{O}_{2} / 45_{2} / 90_{2}\right] \mathrm{s}$ ) plate (clamped, $r=6)$

\begin{tabular}{|c|c|c|c|c|c|c|c|}
\hline \multirow{2}{*}{$\mathbf{a} / \mathbf{b}$} & \multicolumn{7}{|c|}{ Critical buckling load (N/m) } \\
\cline { 2 - 8 } & $\mathbf{n}=\mathbf{1}$ & $\mathbf{n}=\mathbf{2}$ & $\mathbf{n}=\mathbf{4}$ & $\mathbf{n = 6}$ & $\mathbf{n}=\mathbf{8}$ & $\mathbf{n}=\mathbf{1 0}$ & Rectangle \\
\hline 1 & 248012 & 225054 & 225518 & 228595 & 231984 & 235721 & 227709 \\
\hline
\end{tabular}


Table 9 Critical buckling load $N_{c r}(\mathrm{~N} / \mathrm{m})$ of super-elliptical LT1 ( [-4 $\left.45_{2} / 0_{2} / 45_{2} / 90_{2}\right] \mathrm{s}$ ) plate (clamped, $r=6)$ (continue)

\begin{tabular}{|c|c|c|c|c|c|c|c|}
\hline \multirow{2}{*}{$\mathbf{a} / \mathbf{b}$} & \multicolumn{7}{|c|}{ Critical buckling load (N/m) } \\
\cline { 2 - 8 } & $\mathbf{n = 1}$ & $\mathbf{n = 2}$ & $\mathbf{n = 4}$ & $\mathbf{n = 6}$ & $\mathbf{n = 8}$ & $\mathbf{n = 1 0}$ & Rectangle \\
\hline 1.2 & 196040 & 176456 & 176691 & 179033 & 181661 & 184591 & 178374 \\
\hline 1.4 & 167180 & 150143 & 150208 & 152135 & 154293 & 156713 & 151954 \\
\hline 1.6 & 149911 & 134807 & 134727 & 136389 & 138235 & 140278. & 136733 \\
\hline 1.8 & 138913 & 125319 & 125108 & 126581 & 128189 & 129943. & 127432 \\
\hline 2.0 & 131522 & 119149 & 118819 & 120141 & 121554 & 123088 & 121464 \\
\hline $\mathbf{b / a}$ & & & & & & & \\
\hline 1.0 & 248012. & 225054. & 225518 & 228595 & 231984 & 235721 & 227709 \\
\hline 1.2 & 227783 & 209483. & 210036 & 212935 & 216001 & 219284 & 212665 \\
\hline 1.4 & 217549. & 202952 & 203603 & 206363 & 209136 & 211999 & 206921 \\
\hline 1.6 & 211801 & 200298 & 201071 & 203670 & 206139 & 208623 & 205120 \\
\hline 1.8 & 208244 & 199361 & 200271 & 202680 & 204861 & 207003 & 205019 \\
\hline 2 & 205856 & 199189 & 200237 & 202439 & 204350 & 206151 & 205632 \\
\hline
\end{tabular}

\subsection{Effect of plate thickness}

Table 10 - Critical buckling load $N_{c r}(\mathrm{~N} / \mathrm{m})$ of different thinner or thicker super-elliptical plates (simply supported, $r=6, n=1$ )

\begin{tabular}{|c|c|c|c|c|c|c|}
\hline \multirow{3}{*}{$\mathbf{a} / \mathbf{b}$} & \multicolumn{6}{|c|}{ Critical buckling load (N/m) } \\
\hline & \multicolumn{2}{|c|}{$\begin{array}{c}{\left[-45_{2} / 0_{2} / 45_{2} / 900_{2}\right] \mathrm{s}} \\
(\mathrm{t}=3.2 \mathrm{~mm})\end{array}$} & \multicolumn{2}{|c|}{$\begin{array}{c}{\left[-45_{3} / 0_{3} / 45_{3} / 900_{3}\right] \mathrm{s}} \\
(\mathrm{t}=4.8 \mathrm{~mm})\end{array}$} & \multicolumn{2}{|c|}{$\begin{array}{l}{\left[-45_{4} / 0_{4} / 45_{4} / 90_{4}\right] \mathrm{s}(\mathrm{t}=6.4} \\
\mathrm{mm})\end{array}$} \\
\hline & $\begin{array}{l}\text { Rayleigh- } \\
\text { Ritz }\end{array}$ & FEM & $\begin{array}{l}\text { Rayleigh- } \\
\text { Ritz }\end{array}$ & FEM & $\begin{array}{l}\text { Rayleigh- } \\
\text { Ritz }\end{array}$ & FEM \\
\hline 1 & 72129.6 & 71104 & 243394 & 237267 & 576957 & 553980 \\
\hline 1.2 & 56678.2 & 55956 & 189291 & 187189 & 449779 & 439457 \\
\hline 1.4 & 48209.8 & 47562 & 159836 & 159295 & 380402 & 373716 \\
\hline 1.6 & 43197.7 & 42548 & 142542 & 142576 & 339570 & 334755 \\
\hline 1.8 & 40029.5 & 39345 & 131703 & 131866 & 313916 & 309727 \\
\hline 2 & 37906.3 & 37168 & 124503 & 124581 & 296830 & 292680 \\
\hline \multirow{3}{*}{$\mathbf{b} / \mathbf{a}$} & \multicolumn{6}{|c|}{ Critical buckling load (N/m) } \\
\hline & \multicolumn{2}{|c|}{$\begin{array}{l}{\left[-45_{2} / 0_{2} / 45_{2} / 90_{2}\right] \mathrm{s}} \\
(\mathrm{t}=3.2 \mathrm{~mm})\end{array}$} & \multicolumn{2}{|c|}{$\begin{array}{c}{\left[-45_{3} / 0_{3} / 45_{3} / 90_{3}\right] \mathrm{s}} \\
(\mathrm{t}=4.8 \mathrm{~mm})\end{array}$} & \multicolumn{2}{|c|}{$\begin{array}{c}{\left[-45_{3} / 0{ }_{3} / 45_{3} / 90_{3}\right] \mathrm{s}} \\
(\mathrm{t}=4.8 \mathrm{~mm})\end{array}$} \\
\hline & $\begin{array}{l}\text { Rayleigh- } \\
\text { Ritz }\end{array}$ & FEM & $\begin{array}{l}\text { Rayleigh- } \\
\text { Ritz }\end{array}$ & FEM & $\begin{array}{l}\text { Rayleigh- } \\
\text { Ritz }\end{array}$ & FEM \\
\hline 1 & 72129.6 & 71104 & 243394 & 237267 & 576957 & 553980 \\
\hline 1.2 & 66815.0 & 65754 & 227851 & 219525 & 538753 & 512939 \\
\hline
\end{tabular}


Table 10 - Critical buckling load $N_{c r}(\mathrm{~N} / \mathrm{m})$ of different thinner or thicker super-elliptical plates (simply supported, $r=6, n=1$ ) (continue)

\begin{tabular}{|c|c|c|c|c|c|c|}
\hline \multirow{3}{*}{$\mathbf{b} / \mathbf{a}$} & \multicolumn{6}{|c|}{ Critical buckling load (N/m) } \\
\hline & \multicolumn{2}{|c|}{$\begin{array}{c}{\left[-45_{2} / 0{ }_{2} / 45_{2} / 90_{2}\right] \mathrm{s}} \\
(\mathrm{t}=3.2 \mathrm{~mm})\end{array}$} & \multicolumn{2}{|c|}{$\begin{array}{c}{\left[-45_{3} / 00_{3} / 45_{3} / 900_{3}\right] \mathrm{s}} \\
(t=4.8 \mathrm{~mm})\end{array}$} & \multicolumn{2}{|c|}{$\begin{array}{c}{\left[-45_{3} / 0{ }_{3} / 45_{3} / 90_{3}\right] \mathrm{s}} \\
(\mathrm{t}=4.8 \mathrm{~mm})\end{array}$} \\
\hline & $\begin{array}{c}\text { Rayleigh- } \\
\text { Ritz }\end{array}$ & FEM & $\begin{array}{l}\text { Rayleigh- } \\
\text { Ritz }\end{array}$ & FEM & $\begin{array}{l}\text { Rayleigh- } \\
\text { Ritz }\end{array}$ & FEM \\
\hline 1.4 & 64334.6 & 63194 & 221132 & 210982 & 521865 & 493092 \\
\hline 1.6 & 63049.7 & 61796 & 217934 & 206320 & 513614 & 482264 \\
\hline 1.8 & 62278.9 & 60889 & 216109 & 203320 & 508829 & 475294 \\
\hline 2 & 61729.0 & 60272 & 214780 & 201239 & 505368 & 470491 \\
\hline
\end{tabular}

Table 11 - Critical buckling load $N_{c r}(\mathrm{~N} / \mathrm{m})$ of different thinner or thicker super-elliptical plates (clamped, $r=6, n=1$ )

\begin{tabular}{|c|c|c|c|}
\hline \multirow{3}{*}{$\mathbf{a} / \mathbf{b}$} & \multicolumn{3}{|c|}{ Critical buckling load (N/m) } \\
\hline & {$\left[-45_{2} / 02 / 45_{2} / 90_{2}\right] \mathrm{s}$} & {$\left[-45_{3} / 00_{3} / 45_{3} / 90_{3}\right] s$} & {$\left[-45_{4} / 0_{4} / 45_{4} / 90_{4}\right] \mathrm{s}$} \\
\hline & $\mathrm{t}=3.2 \mathrm{~mm}$ & $\mathrm{t}=4.8 \mathrm{~mm}$ & $\mathrm{t}=6.4 \mathrm{~mm}$ \\
\hline 1 & 248012 & 834717 & 1979940 \\
\hline 1.2 & 196040. & 653874 & 1554180 \\
\hline 1.4 & 167180 & 553977 & 1318610 \\
\hline 1.6 & 149911 & 494608 & 1178330 \\
\hline 1.8 & 138913 & 457075 & 1089450 \\
\hline 2 & 131522 & 432041 & 1030030 \\
\hline \multirow{3}{*}{$\mathbf{b} / \mathbf{a}$} & \multicolumn{3}{|c|}{ Critical buckling load (N/m) } \\
\hline & {$\left[-45_{2} / 02 / 45_{2} / 90_{2}\right] \mathrm{s}$} & {$\left[-45_{3} / 0_{3} / 45_{3} / 90_{3}\right] \mathrm{s}$} & {$\left[-45_{4} / 0_{4} / 45_{4} / 90_{4}\right] \mathrm{s}$} \\
\hline & $\mathrm{t}=3.2 \mathrm{~mm}$ & $\mathrm{t}=4.8 \mathrm{~mm}$ & $\mathrm{t}=6.4 \mathrm{~mm}$ \\
\hline 1 & 248012. & 834717 & 1979940 \\
\hline 1.2 & 227783 & 773429 & 1830780 \\
\hline 1.4 & 217549 . & 743275 & 1756840 \\
\hline 1.6 & 211801 & 726584 & 1715790 \\
\hline 1.8 & 208244 & 716238 & 1690380 \\
\hline 2 & 205856 & 709216 & 1673220 \\
\hline
\end{tabular}


Table 12 - Critical buckling load $N_{c r}(\mathrm{~N} / \mathrm{m})$ of different thinner or thicker super-elliptical plates (simply supported, $r=6, n=10$ )

\begin{tabular}{|c|c|c|c|}
\hline \multirow{3}{*}{$\mathbf{a} / \mathbf{b}$} & \multicolumn{3}{|c|}{ Critical buckling load (N/m) } \\
\hline & {$\left[-45_{2} / 02 / 45_{2} / 90_{2}\right] \mathrm{s}$} & {$\left[-45_{3} / 0_{3} / 45_{3} / 90_{3}\right] s$} & {$\left[-45_{4} / 0_{4} / 45_{4} / 90_{4}\right] \mathrm{S}$} \\
\hline & $\mathrm{t}=3.2 \mathrm{~mm}$ & $\mathrm{t}=4.8 \mathrm{~mm}$ & $\mathrm{t}=6.4 \mathrm{~mm}$ \\
\hline 1 & 99773.5 & 329924 & 786523 \\
\hline 1.2 & 79719. & 261649 & 625061 \\
\hline 1.4 & 66955.8 & 218973 & 523162 \\
\hline 1.6 & 58289.4 & 190137 & 454730 \\
\hline 1.8 & 52089.7 & 169687 & 405734 \\
\hline 2 & 47474.9 & 154633 & 369886 \\
\hline \multirow{3}{*}{$\mathbf{b} / \mathbf{a}$} & \multicolumn{3}{|c|}{ Critical buckling load (N/m) } \\
\hline & {$\left[-45_{2} / 0_{2} / 45_{2} / 90_{2}\right] \mathrm{s}$} & {$\left[-45_{3} / 0_{3} / 45_{3} / 90_{3}\right] s$} & {$\left[-45_{4} / 0_{4} / 45_{4} / 90_{4}\right] \mathrm{s}$} \\
\hline & $\mathrm{t}=3.2 \mathrm{~mm}$ & $\mathrm{t}=4.8 \mathrm{~mm}$ & $\mathrm{t}=6.4 \mathrm{~mm}$ \\
\hline 1 & 99773.5 & 329924 & 786523 \\
\hline 1.2 & 88295.5 & 294463 & 700661 \\
\hline 1.4 & 80591.1 & 271005 & 643257 \\
\hline 1.6 & 75087. & 254299 & 602562 \\
\hline 1.8 & 71001.7 & 241897 & 572141 \\
\hline 2 & 67858.6 & 232343 & 548957 \\
\hline
\end{tabular}

In this section, critical buckling loads for super-elliptical plates for three selected different thicknesses (3.2, 4.8 and $6.4 \mathrm{~mm})$, super-elliptical powers ( $\mathrm{n}=1$ and 10$)$, boundary conditions (clamped and simply supported) and aspect ratios (a/b and b/a) were investigated. The results are given in Table 10-13. From these results, critical buckling loads increase with the increase of the plate thickness as expected. As may be seen from the Tables (10-13), critical buckling loads decreases with the increase of the aspect ratio. Critical buckling loads of clamped plates are higher than simply supported plates for all cases.

Table 13 - Critical buckling load $N_{c r}(\mathrm{~N} / \mathrm{m})$ of different thinner or thicker super-elliptical plates (clamped, $r=6, n=10$ )

\begin{tabular}{|c|c|c|c|}
\hline \multirow{3}{*}{$\mathbf{a} / \mathbf{b}$} & \multicolumn{3}{|c|}{ Critical buckling load (N/m) } \\
\hline & {$\left[-45_{2} / 0_{2} / 45_{2} / 90_{2}\right] \mathrm{s}$} & {$\left[-45_{3} / 0_{3} / 45_{3} / 90_{3}\right] \mathrm{s}$} & {$\left[-45_{4} / 0_{4} / 45_{4} / 90_{4}\right] \mathrm{s}$} \\
\hline & $\mathrm{t}=3.2 \mathrm{~mm}$ & $\mathrm{t}=4.8 \mathrm{~mm}$ & $\mathrm{t}=6.4 \mathrm{~mm}$ \\
\hline 1 & 235721 & 797535 & 1889260 \\
\hline 1.2 & 184591 & 617921 & 1467230 \\
\hline 1.4 & 156713 & 520596 & 1238340 \\
\hline
\end{tabular}


Table 13 - Critical buckling load $N_{c r}(\mathrm{~N} / \mathrm{m})$ of different thinner or thicker super-elliptical plates (clamped, $r=6, n=10)$ (continue)

\begin{tabular}{|c|c|c|c|}
\hline \multirow{3}{*}{$\mathbf{a} / \mathbf{b}$} & \multicolumn{3}{|c|}{ Critical buckling load (N/m) } \\
\hline & {$\left[-45_{2} / 00_{2} / 45_{2} / 90_{2}\right] \mathrm{s}$} & {$\left[-45_{3} / 0_{3} / 45_{3} / 90_{3}\right] \mathrm{s}$} & {$\left[-45_{4} / 0_{4} / 45_{4} / 90_{4}\right] \mathrm{s}$} \\
\hline & $\mathrm{t}=3.2 \mathrm{~mm}$ & $\mathrm{t}=4.8 \mathrm{~mm}$ & $\mathrm{t}=6.4 \mathrm{~mm}$ \\
\hline 1.6 & 140278 & 463805 & 1104200 \\
\hline 1.8 & 129943. & 428404 & 1020290 \\
\hline 2 & 123088 & 404905 & 964996 \\
\hline \multirow{3}{*}{$\mathbf{b} / \mathbf{a}$} & \multicolumn{3}{|c|}{ Critical buckling load (N/m) } \\
\hline & {$\left[-45_{2} / 0_{2} / 45_{2} / 90_{2}\right] s$} & {$\left[-45_{3} / 0_{3} / 45_{3} / 90_{3}\right] s$} & {$\left[-45_{4} / 0_{4} / 45_{4} / 90_{4}\right] \mathrm{s}$} \\
\hline & $\mathrm{t}=3.2 \mathrm{~mm}$ & $\mathrm{t}=4.8 \mathrm{~mm}$ & $\mathrm{t}=6.4 \mathrm{~mm}$ \\
\hline 1 & 235721 & 797535 & 1889260 \\
\hline 1.2 & 219284 & 750242 & 1772210 \\
\hline 1.4 & 211999 & 731457 & 1724620 \\
\hline 1.6 & 208623 & 724438 & 1705180 \\
\hline 1.8 & 207003 & 722194 & 1697880 \\
\hline 2 & 206151 & 721874 & 1695730 \\
\hline
\end{tabular}

\subsection{Effect of lamination types, boundary conditions and aspect ratios}

Twenty-eight different types of quasi-isotropic, cross-ply and angle-ply plates shown in Table 3 are used for the calculations of the critical buckling loads $\mathrm{N}_{\mathrm{cr}}(\mathrm{N} / \mathrm{m})$ of super-elliptical plates $(r=6$ and $n=10)$ under simply supported or clamped conditions, and the results are presented in Figure 2-5.

It can be seen from the results that the critical buckling loads depend on the types of lamination. Critical buckling loads decrease with the increase of aspect ratios $(a / b$ and $b / a)$ and change with the selection of the short half side of the plates ( $a$ or b). It is also observed that the results change with the boundary restraints. Critical buckling loads for simply supported conditions are lower than those for clamped conditions. The lowest critical buckling load of the plates seems to decrease as the aspect ratio increases for both the simply supported case and the clamped case.

The principal objective of this parametric study is to seek the best possible lamination among 28 alternatives under uniform in-plane load, which is in fact the one with the highest value of lowest critical buckling load.

From the Figure 2-5, it is seen that the critical buckling values of 24 different quasi-isotropic plates (LT1-24) in pairs and 2 different types of angle-ply (LT27-28) plates have the same values. 


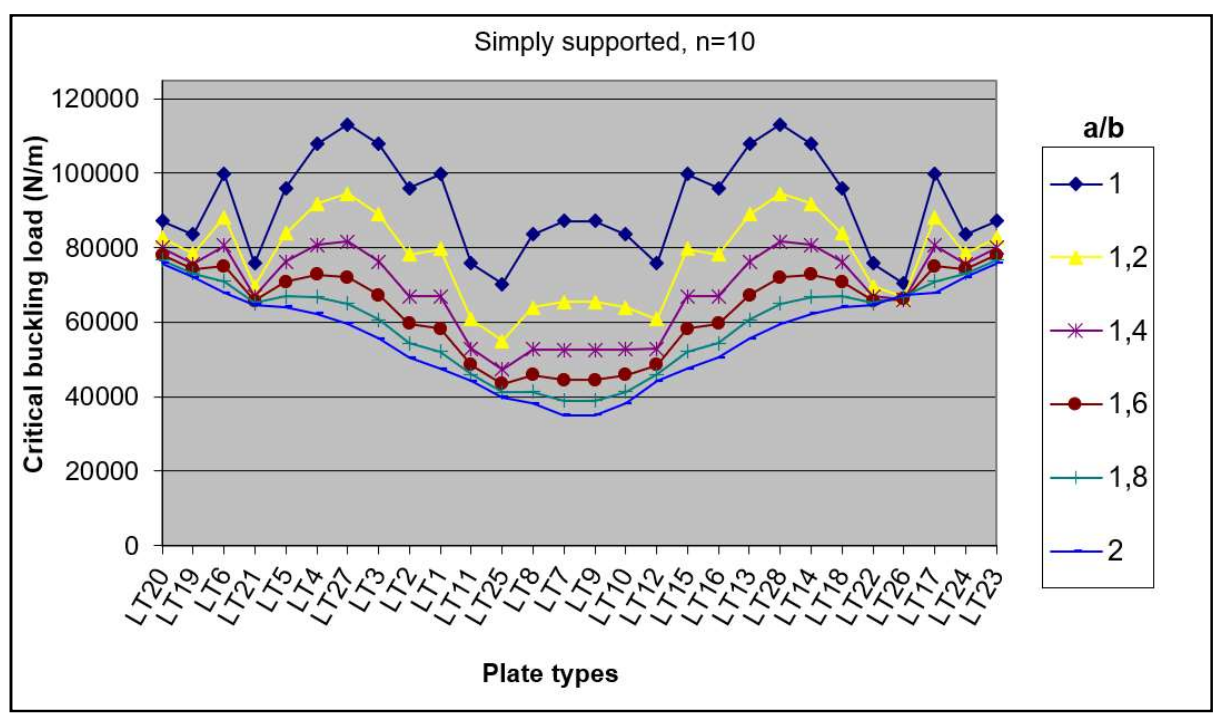

Figure 2 - Critical buckling load $N_{c r}(\mathrm{~N} / \mathrm{m})$ of super-elliptical plates (simply supported $r=6, n=10$ )

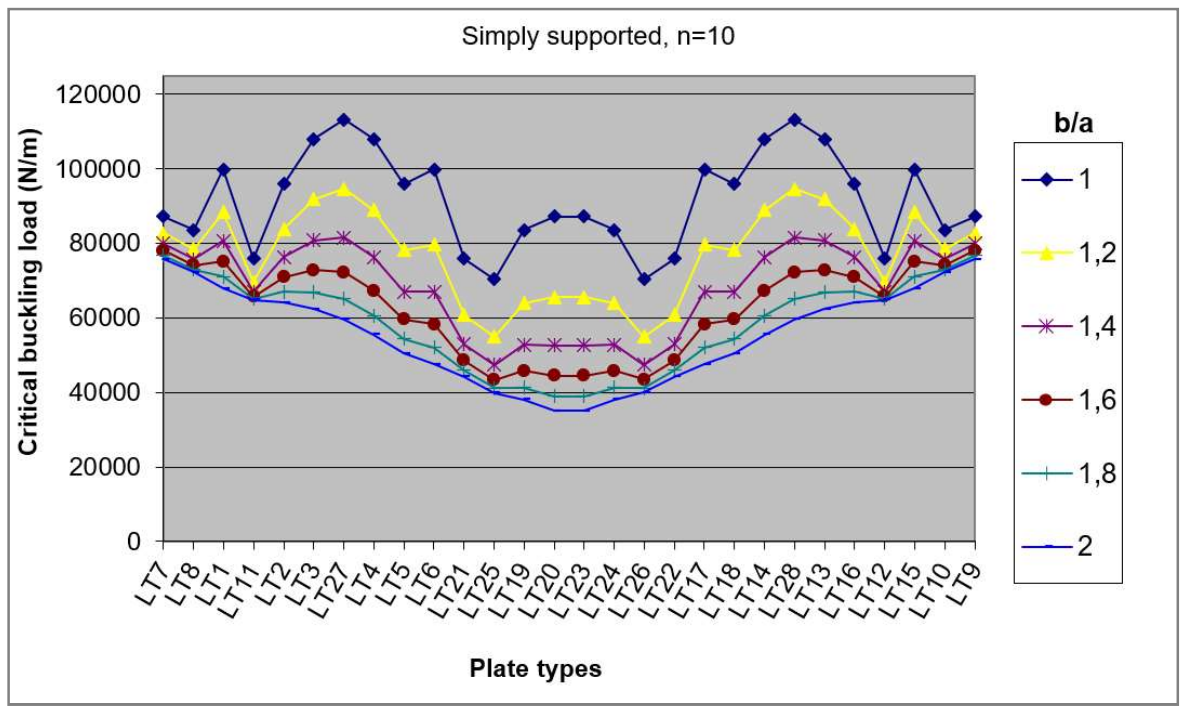

Figure 3 - Critical buckling load $N_{c r}(\mathrm{~N} / \mathrm{m})$ of super-elliptical plates (simply supported $r=6$, $n=10$ ) 


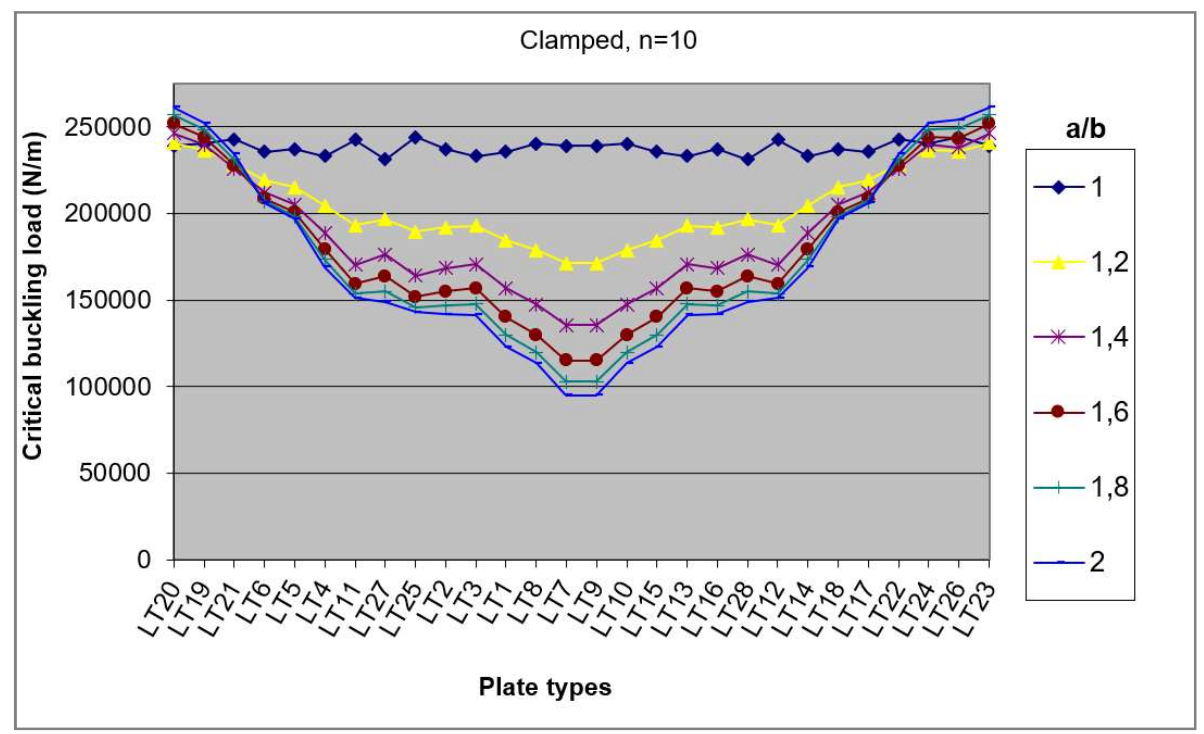

Figure 4 - Critical buckling load $N_{c r}(N / m)$ of super-elliptical plates (clamped) $r=6, n=10$

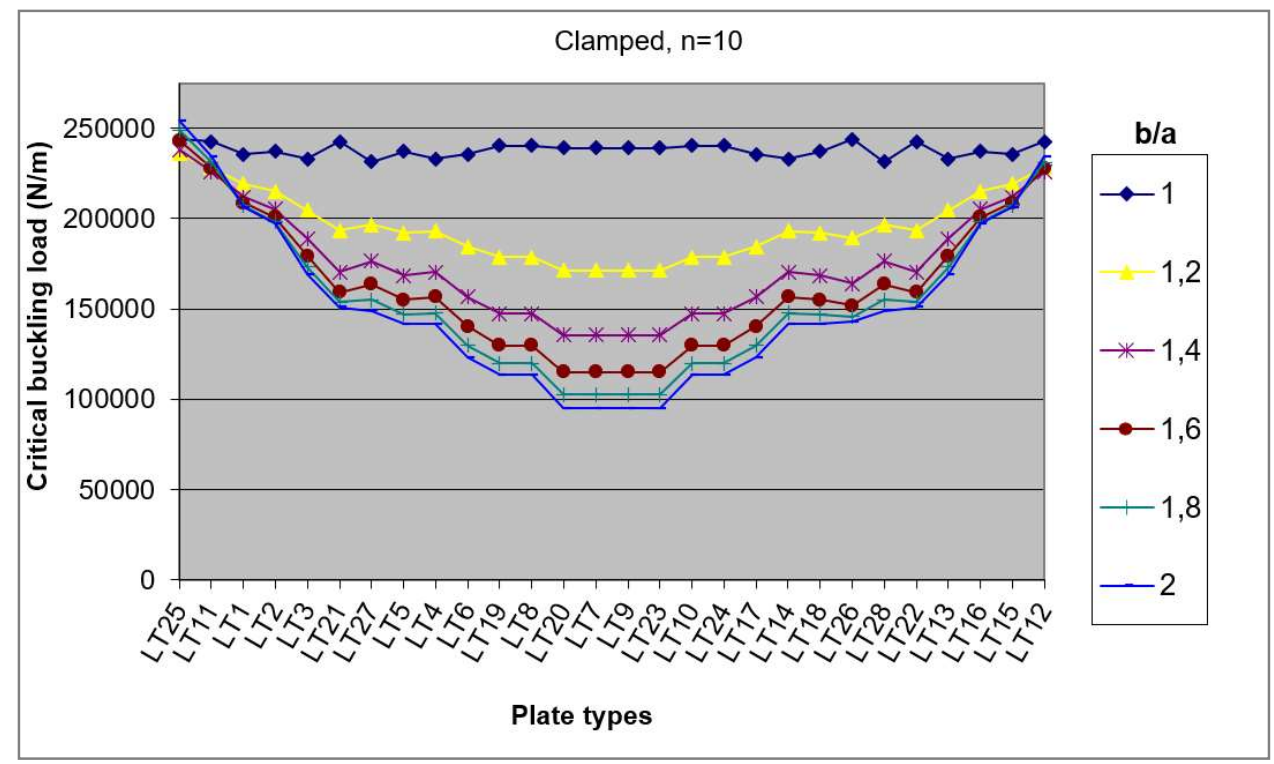

Figure 5 - Critical buckling load $N_{c r}(N / m)$ of super-elliptical plates (clamped) $r=6, n=10$ 


\section{CONCLUSIONS}

Buckling analyses of elliptical and super-elliptical quasi-isotropic, cross-ply and angle-ply plates have been carried out based on the Classical Lamination Plate Theory (CLPT) by using the Rayleigh-Ritz Method for different boundary restraints (clamped or simply supported). Computations were done by Wolfram Mathematica [34] and MATLAB [35] software platforms.

The critical buckling loads of plates with different super-elliptical powers (n), thicknesses, aspect ratios and lamination types were investigated. The verification of the isotropic case for two different boundary conditions (clamped and simply supported) and for different aspect ratios (1 to 5) was compared with some available studies in the literature and reliable convergence was obtained.

Convergence studies of up to five terms were carried out with the Rayleigh-Ritz Method and the Galerkin Method, known as a powerful weighted residual method using three different shape functions for clamped and simply supported boundary conditions in Section 3.4. From these results, it was observed that buckling analysis for super-elliptical plates $(n=1,10)$, for simply supported or clamped boundary conditions, Rayleigh-Ritz Method with suitable shape function is the more proper method in terms of less computational time and accurate results.

It can be seen from the convergence analysis of the LT1 $\left(\left[-45_{2} / 0_{2} / 45_{2} / 90_{2}\right] \mathrm{s}\right)$ plate that reasonable accuracy was obtained for a trial function with 10 terms with Rayleigh-Ritz Method. It was observed that critical buckling loads of plates are influenced by the change of the super-elliptical power, lamination types, boundary conditions, thickness and aspect ratios. It was also observed that critical buckling loads of simply supported super-elliptical plates are lower than those of clamped super-elliptical plates.

From the tabulated results and graphics critical buckling loads increase with an increase in the thickness. However, they generally decrease with increase of the aspect ratios. It can also be concluded that some lamination types have favorable circumstances with regard to the critical buckling load, as given in Section 3.2.

It was observed that from the results of highest value for the lowest critical buckling loads $\left(\mathrm{N}_{\mathrm{cr}}\right)$ of super-elliptical plates $(\mathrm{n}=10)$, angle-ply plates are more advantageous than cross-ply and quasi-isotropic plates for lowest aspect ratio is $(\mathrm{a} / \mathrm{b}=1,1.2$ and 1.4$)$. Besides, quasiisotropic plates are more advantageous than others for highest aspect ratios $(\mathrm{a} / \mathrm{b}=1.6,1.8$ and 2) similar to the rectangular plate in previous work [30] for the simply supported boundary condition. However, quasi-isotropic plates are more advantageous than others for all aspect ratios for clamped boundary conditions. From the results of elliptical plates $(n=1)$ for simply supported and clamped boundary conditions, quasi-isotropic plates are more advantageous than angle-ply and cross-ply plates for all aspect ratios.

Critical buckling loads of symmetrically laminated elliptical plates (super-elliptical power $\mathrm{n}=1$ ) have been demonstrated in Appendix A (Figures A1.-A4.) for designers. Some mode shapes of laminated quasi-isotropic, cross-ply and angle-ply elliptic plate types $(n=1)$ in simple support boundary condition was obtained with FEM software ANSYS [36] and presented in Appendix B (Figures B1, B2 and B3.).

Consequently, in the preliminary design of composite structures, it is possible to obtain optimum data sets with parametric analyzes as illustrated in this study. The Rayleigh-Ritz 
method gives faster and more convenient results than the Galerkin Method for buckling analysis of elliptical and super-elliptical plates when the appropriate shape function is selected.

\section{Acknowledgements}

The authors dedicate this article to Prof. Dr. Uğur GÜVEN (Yildiz Technical University).

\section{References}

[1] Shenoi, R.A. and Wellicome, J.F.), Composite Materials in Maritime Structures, (Fundamental Aspects) Volume-I. Cambridge University Press, NY., 1993a.

[2] Shenoi, R.A. and Wellicome, J.F, Composite Materials in Maritime Structures, (Practical Considerations) Volume-II. Cambridge University Press, NY., 1993 b.

[3] Mouritz, A.P., Gellert, E., Burchill, P. and Challis, K., Review of advanced composite structures for naval ships and submarines, Compos. Struct. 53(1):21-41, 2001.

[4] Altekin, M., Free transverse vibration of shear deformable super-elliptical plates, Wind and Struct. 24(4),307-331, 2017.

[5] Kumar, Y., The Rayleigh-Ritz method for linear dynamic, static and buckling behavior of beams, shells and plates: A literature review,. J. Vibr. and Cont. 24(7): 1205-1227, 2018.

[6] Timoshenko, S.P. and Gere, J.M., Theory of Elastic Stability, 2nd Edition. McGrawHill Book Company, USA, 1961.

[7] Szilard, R., Theories and Applications of Plate Analysis: Classical Numerical and Engineering Methods, John Wiley \& Sons, Inc., Hoboken, NJ, USA, 2004.

[8] Dawe, D.J. and Craig, T.J., The vibration and stability of symmetrically-laminated composite rectangular plates subjected to in-plane stresses, Compos. Struct.5(4): 281307, 1986.

[9] Leissa, A.W., A review of laminated composite plate buckling, App. Mech. Rev. 40(5), 1987.

[10] Aiello, M.A. and Ombres, L., Buckling and vibrations of unsymmetric laminates resting on elastic foundations under in-plane and shear forces, Compos. Struct. 44: 3141, 1999.

[11] Darvizeh, M., Darvizeh A., Ansari, R. and Sharma, C.B., Buckling analysis of generally laminated composite plates (generalized differential quadrature rules versus RayleighRitz method, Compos. Struct. 63:69-74, 2004.

[12] Reddy, J.N., Mechanics of laminated composite plates and shells: Theory and Analysis, 2nd ed., Boca Raton, FL, CRC Press, 2004. 
[13] Shufrin, I., Rabinovitch, O. and Eisenberger, M., Buckling of symmetrically laminated rectangular plates with general boundary conditions - A semi analytical approach, Compos. Struct. 82: 521-531, 2008.

[14] Seifi, R., Khoda-Yari, N. and Hosseini, H., Study of critical buckling loads and modes of cross-ply laminated annular plates, Compos. Part B Eng. 43(2): 422-430, 2012.

[15] Altunsaray, E. and Bayer, İ., Buckling of symmetrically laminated quasi-isotropic thin rectangular plates, Steel and Compos. Struct. 17(3): 305-320, 2014.

[16] Afsharmanesh, B., Ghaheri, A. and Taheri-Behrooz, F., Buckling and vibration of laminated composite circular plate on winkler-type foundation, Steel and Compos. Struct. 17(1): 1-19, 2014.

[17] Ghaheri, A., Keshmiri, A. and Taheri-Behrooz, F., Buckling and vibration of symmetrically laminated composite elliptical plates on an elastic foundation subjected to uniform in-plane force, J. Eng. Mech. 140(7): 04014049-1-10, 2014.

[18] Liew, K.M, Kitipornchai, S. and Lim, C.W., Free vibration analysis of thick superelliptical plates, J. Eng. Mech. 124 (2): 137-145, 1998.

[19] Wang, C.M., Wang, L. and Liew, K.M., Vibration and buckling of super elliptical plates, J. Sound Vib. 171(3): 301-31, 1994.

[20] Altekin, M., Free linear vibration and buckling of super-elliptical plates resting on symmetrically distributed point-supports on the diagonals, Thin Wall. Struct. 46:10661086, 2008.

[21] Hasheminejad, S.M., Keshvari, M.M. and Ashory, M.R., Dynamic stability of superelliptical plates resting on elastic foundations under periodic in-plane loads, J. Eng. Mech. 140(1):172-181, 2014.

[22] Jazi, S.R. and Farhatnia, F., Buckling analysis of functionally graded super elliptical plate using pb-2 Ritz Method, Adv. Mat. Res. Vols.383-390: 5387-5391, 2012.

[23] Sayyad, A.S. and Ghugal, Y.M., On the buckling of isotropic, transversely isotropic and laminated composite rectangular plates, Int. J. Struct. Stab. Dyn. 14(7): 1450020, 2014.

[24] Ghaheri, A., Nosier, A. and Keshmiri. A., Parametric stability of symmetrically laminated composite super-elliptical plates, J. Compos. Mat. 50(28): 3935-3951, 2016.

[25] Zhang, D.G., Nonlinear bending and thermal post-buckling analysis of FGM super elliptical thin plates, Res.\& Rev.: J. Mat. Sci. 5(6): 64-73, 2017.

[26] Altekin, M., Bending of super-elliptical Mindlin plates by finite element method, Teknik Dergi, 29, No:4, 8469-8496, 2018.

[27] Mirzaei, M., Thermal buckling of temperature-dependent composite super elliptical plates reinforced with carbon nanotubes, J. Therm. Str. 41(7): 920-935, 2018.

[28] Altunsaray, E. and Bayer, İ., Deflection and free vibration of symmetrically laminated quasi-isotropic thin rectangular plates for different boundary conditions, Ocean Eng. 57:197-222, 2013. 
[29] Altunsaray, E., Free vibration of symmetrically laminated quasi-isotropic superelliptical thin plates" Steel and Compos. Struct. 29(4): 493-508, 2018.

[30] Altunsaray, E. and Bayer, İ., Buckling Analysis of Symmetrically Laminated Rectangular Thin Plates under Biaxial Compression" Teknik Dergi, 29, No:4, 2021.

[31] Sato, K., Free flexural vibrations of a simply supported elliptical plate subjected to an in-plane force, Theo. App. Mech. Jap. 50: 165-181, 2001.

[32] Sato, K., Vibration and buckling of a clamped elliptical plate on elastic foundation and under uniform in-plane force, Theo. App. Mech. Jap. 51:49-62, 2002.

[33] Tsai, S.W., Composites design. (4th Edition), Think Composites, 1988.

[34] Wolfram Mathematica, Dokuz Eylul University.

[35] MATLAB, Dokuz Eylul University.

[36] ANSYS, Dokuz Eylul University.

\section{APPENDIX A}

In this section, the results of the critical buckling loads found for the simply support and clamped boundary conditions, edge ratios $\mathrm{a} / \mathrm{b}$ and $\mathrm{b} / \mathrm{a}$ by the Rayleigh-Ritz Method analysis of the elliptical plates $(\mathrm{n}=1)$ are shown in (Figure A1-A4).

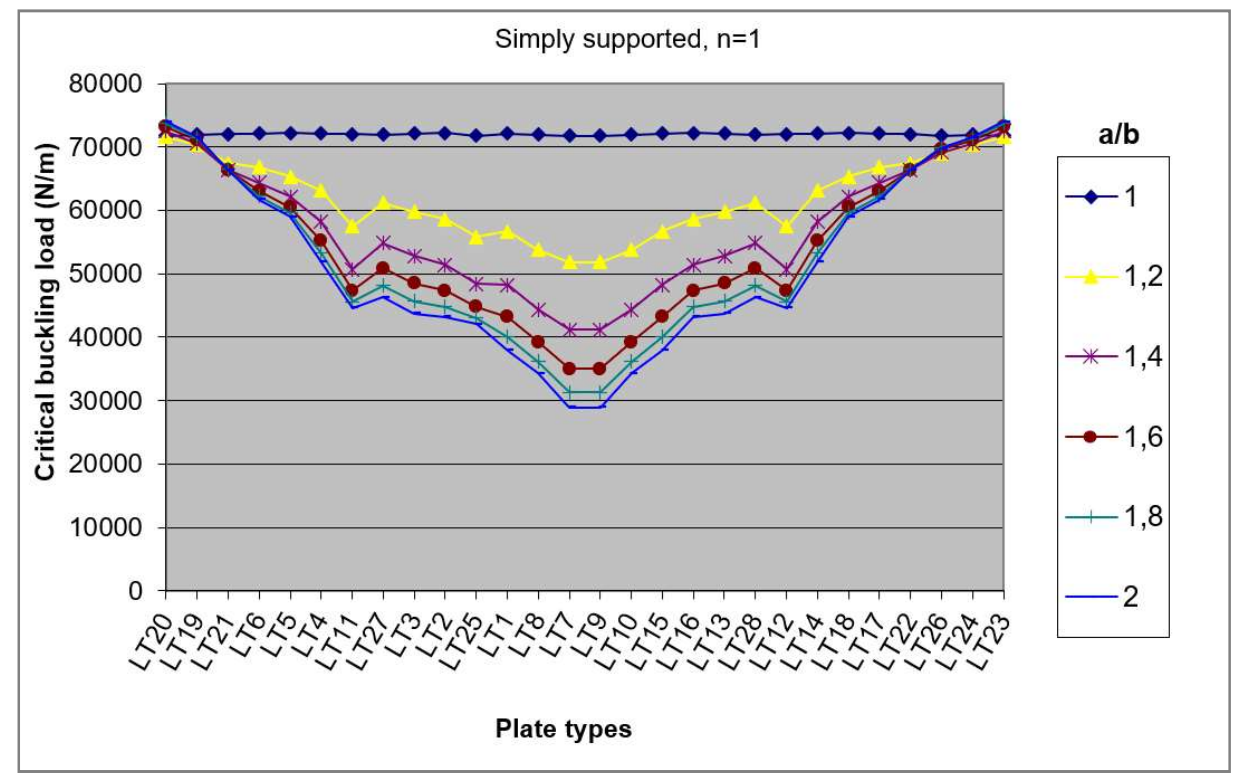

Figure A1 - Critical buckling load Ncr (N/m) of super-elliptical plates (simply supported) $r=6, n=1$ 


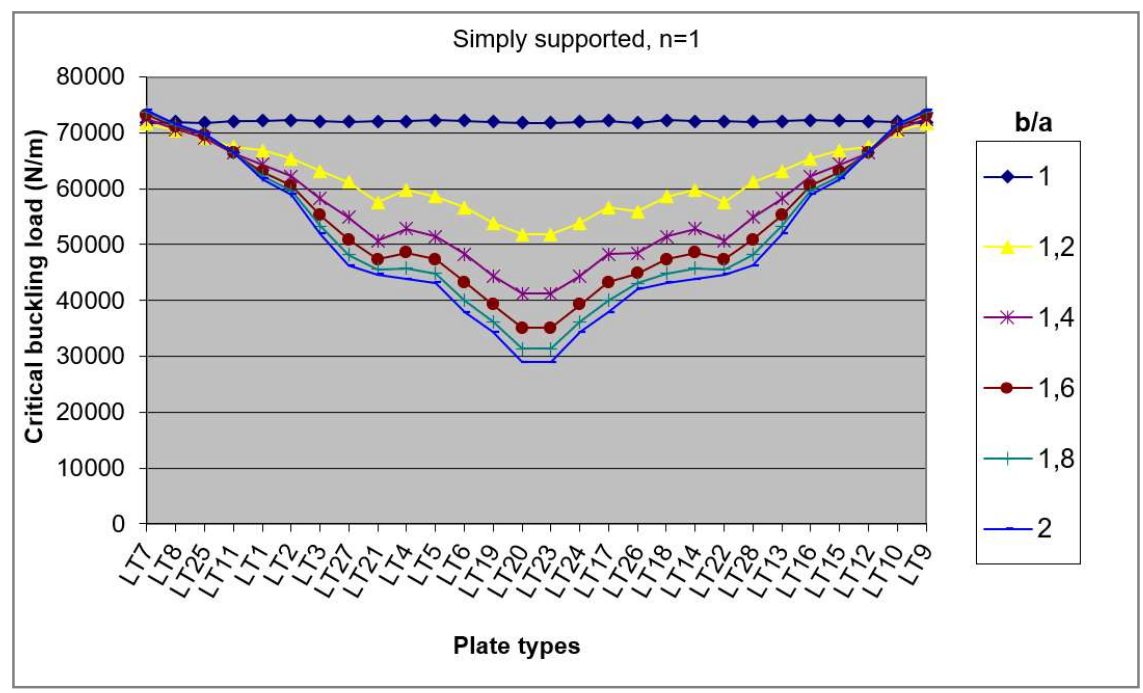

Figure A2 - Critical buckling load Ncr (N/m) of super-elliptical plates (simply supported) $r=6, n=1$

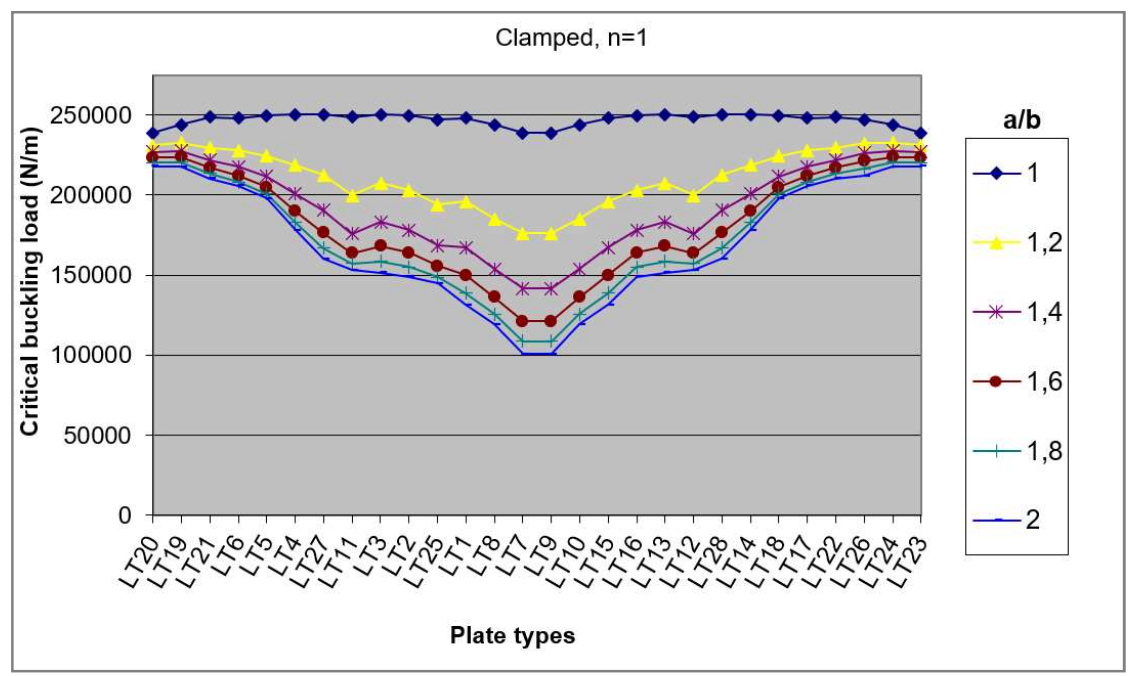

Figure A3 - Critical buckling load Ncr $(N / m)$ of super-elliptical plates (clamped) $r=6, n=1$ 


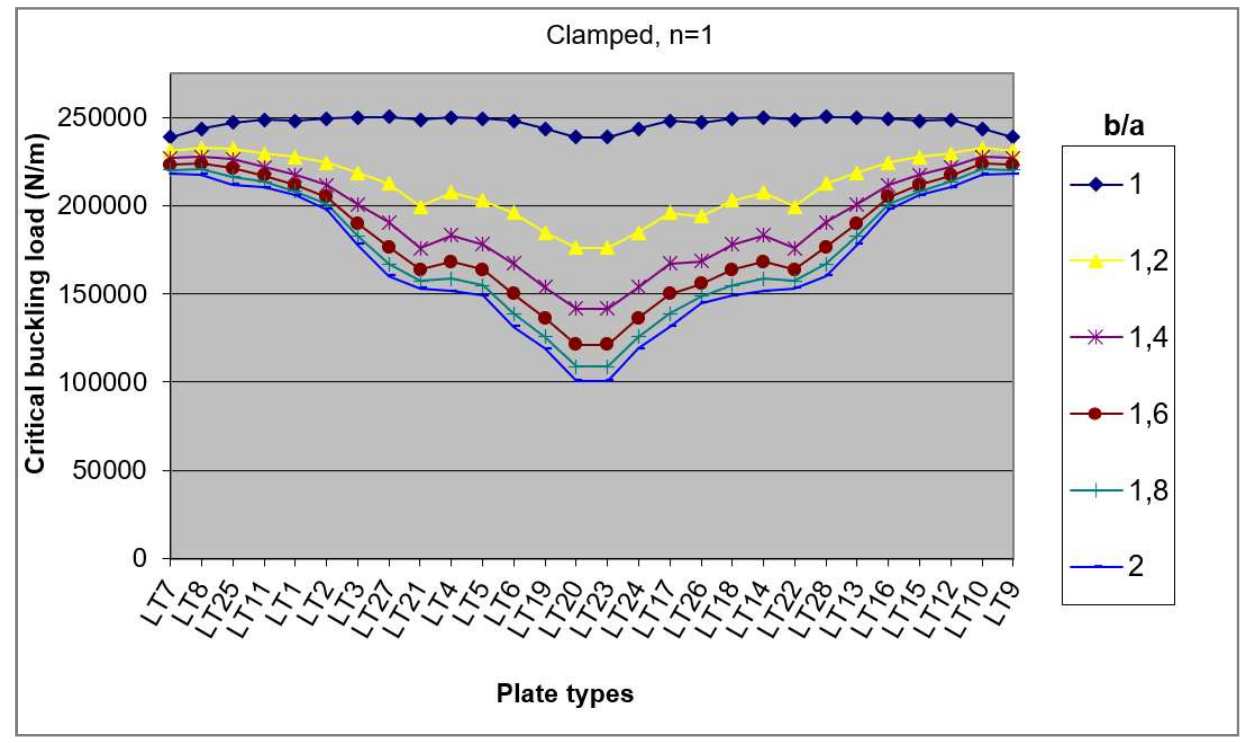

Figure A4 - Critical buckling load Ncr $(\mathrm{N} / \mathrm{m})$ of super-elliptical plates (clamped) $r=6, n=1$

\section{APPENDIX B}

In this section, first three mode shapes of some elliptic plate $(n=1)$ types (quasi-isotropic, cross-ply and angle-ply laminates) in simply supported boundary condition were calculated and plotted in the FEM analysis program ANSYS [36] (Figure B1, B2 and B3). No result could be obtained with the program for the clamped boundary conditions or super-elliptical plates $(\mathrm{n}=10)$.

It may be seen from Figure B1 $(\mathrm{a} / \mathrm{b}=1)$, LT27 (angle-ply plate) has the highest critical buckling loads for mode-1 and mode-2, LT25 (cross-ply plate) has the highest critical buckling load for mode-3. From Figure B2 $(\mathrm{a} / \mathrm{b}=2)$, LT19 (quasi-isotropic plate) has the highest critical buckling loads for mode-1, LT27 (angle-ply plate) has the highest critical buckling loads for mode-2 and LT25 (cross-ply plate) has the highest critical buckling load for mode-3.

Similar to the results found in the previous studies of the authors [30] in which they analyzed rectangular plates, although the critical buckling loads of some plates in super-elliptical plates are the same in this study, these results change when the aspect ratio changes. For instance, LT8 and LT19 plates have equal critical buckling loads for the $a / b=1$ case, but mode shapes are different (Figure B1). However, as seen in Figure B2 and B3, the critical buckling loads and mode shapes of the LT8 and LT19 plates are different in the $a / b=2$ and $b / a=2$ cases.

In general, there are two types of construction systems called transverse system or longitudinal system depending on the placement directions of supporting structural members in composite hull design. In this study, one of the reasons for calculating ratios of $\mathrm{a} / \mathrm{b}$ and $\mathrm{b} / \mathrm{a}$ separately is that the designers would be able to prefer either transverse or longitudinal construction system. For instance, as can be seen in Figure B2 and B3, plate numbered LT8 
gives the same critical buckling values as plate numbered LT19 in case of edge ratio $\mathrm{b} / \mathrm{a}=2$ when the edge ratio is $a / b=2$. It is recommended that a designer may prefer the plate type LT8 for production in the transverse system, and the plate type LT19 for production in the longitudinal construction system.

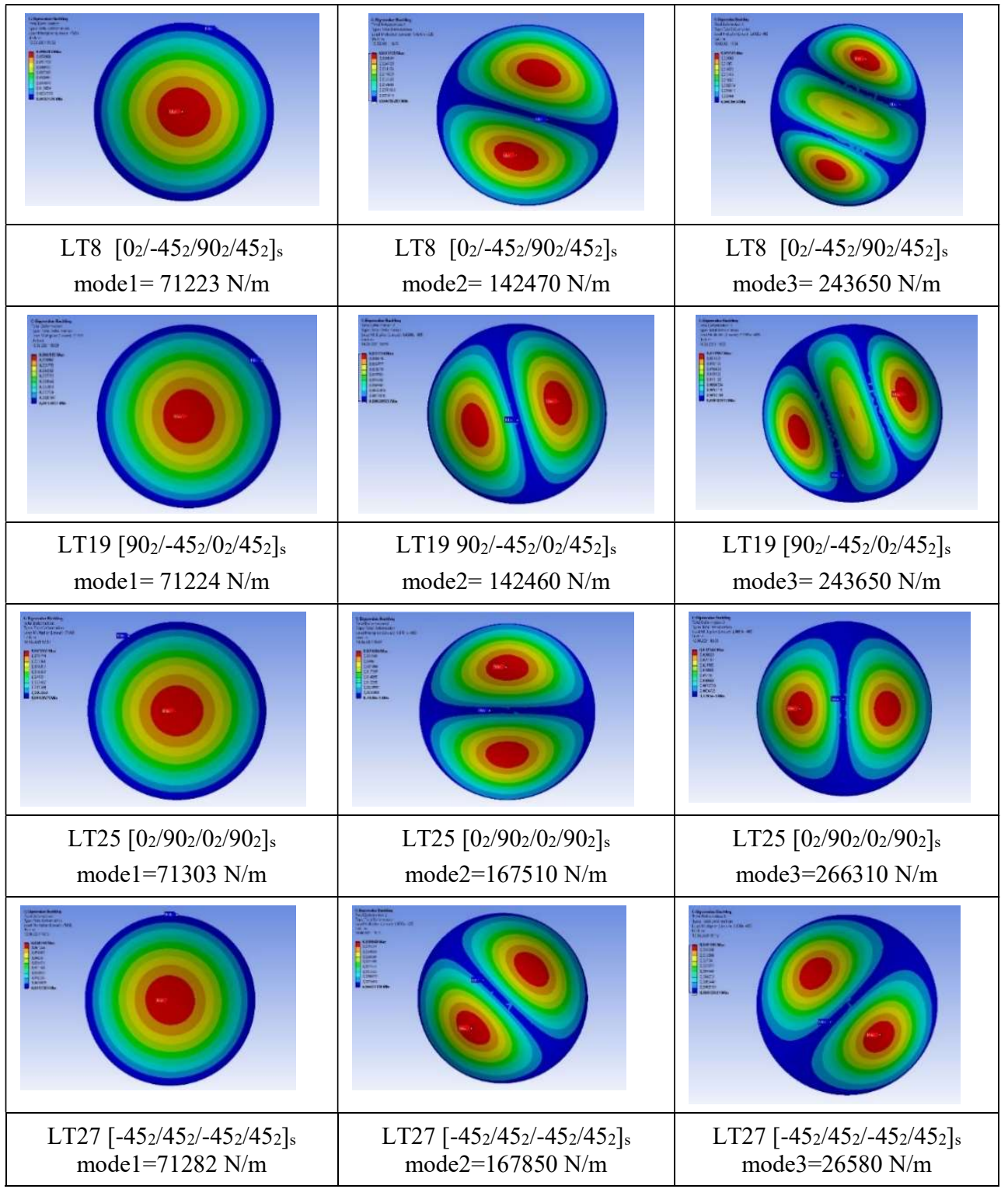

Figure B1 - Some mode shapes of laminated plates (quasi-isotropic, cross-ply, angle-ply) $(a / b=1, n=1)$ 


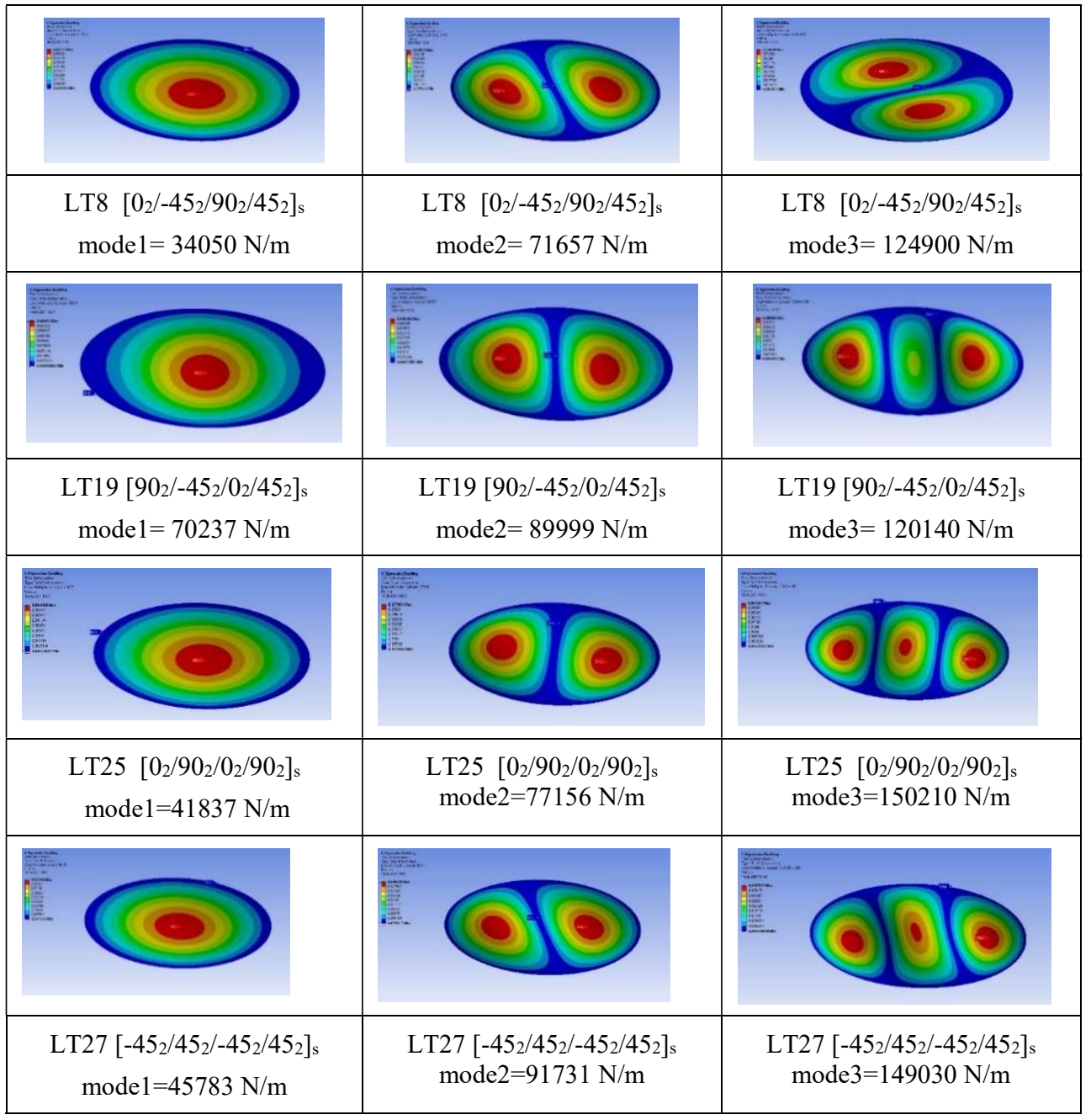

Figure B2 - Some mode shapes of laminated plates (quasi-isotropic, cross-ply, angle-ply) $(a / b=2, n=1)$ 


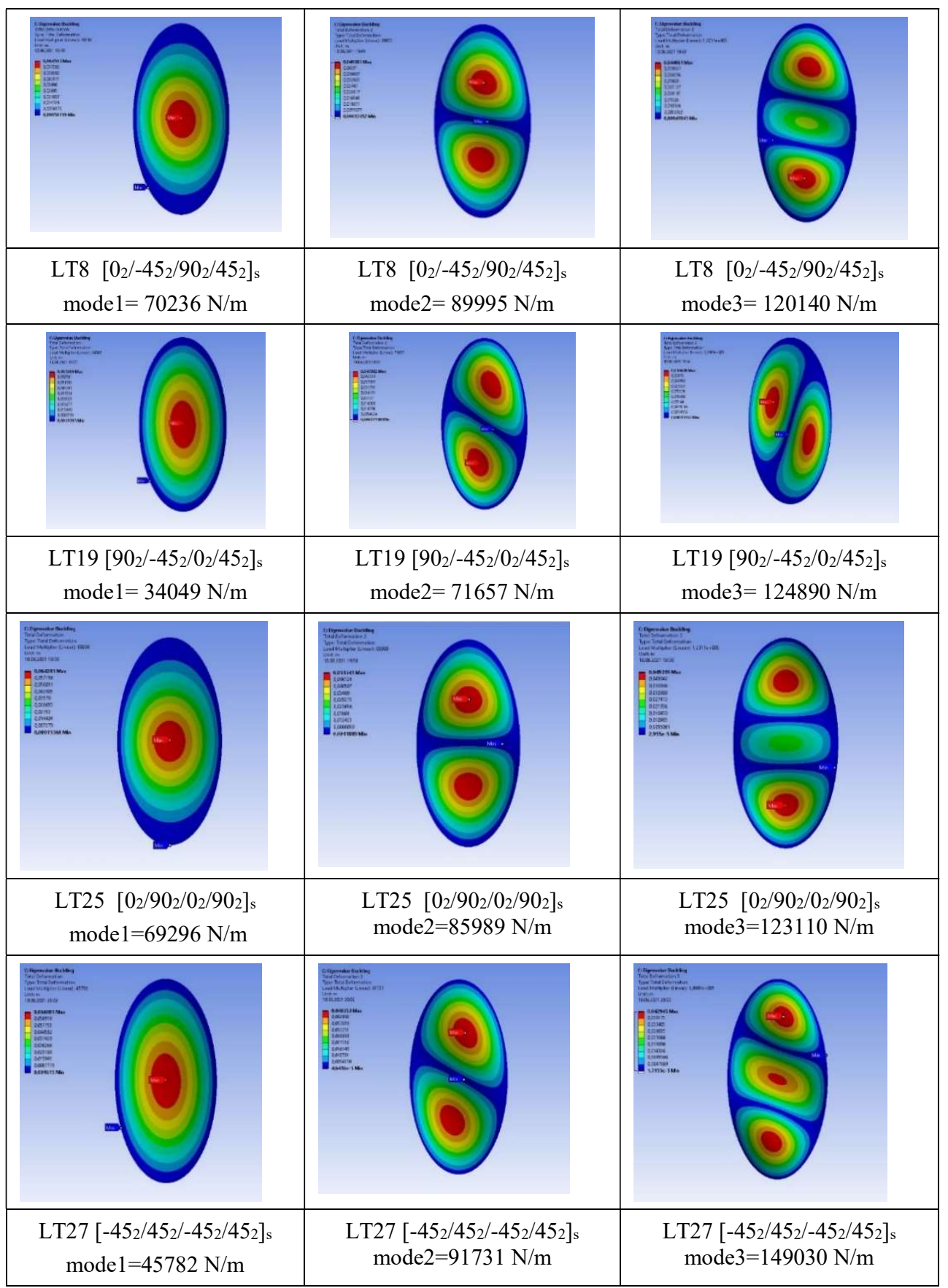

Figure B3 - Some mode shapes of laminated plates (quasi-isotropic, cross-ply, angle-ply) (b/a=2, $n=1)$ 
